\title{
A Caspase Cascade Regulating Developmental Axon Degeneration
}

\author{
David J. Simon, ${ }^{1,2}$ Robby M. Weimer, ${ }^{3}$ Todd McLaughlin, ${ }^{5}$ Dara Kallop, ${ }^{3}$ Karen Stanger, ${ }^{4}$ Jing Yang, ${ }^{1,2}$ \\ Dennis D. M. 0'Leary, ${ }^{5}$ Rami N. Hannoush, ${ }^{4}$ and Marc Tessier-Lavigne ${ }^{1,2}$ \\ ${ }^{1}$ Laboratory of Brain Development and Repair, Rockefeller University, New York, New York 10065, Departments of ${ }^{2}$ Neuroscience, ${ }^{3}$ Biomedical Imaging, \\ and ${ }^{4}$ Early Discovery Biochemistry, Genentech, Inc., South San Francisco, California 94080, and ${ }^{5}$ Molecular Neurobiology Laboratory, The Salk Institute, La \\ Jolla, California 92037
}

Axon degeneration initiated by trophic factor withdrawal shares many features with programmed cell death, but many prior studies discounted a role for caspases in this process, particularly Caspase-3. Recently, Caspase-6 was implicated based on pharmacological and knockdown evidence, and we report here that genetic deletion of Caspase- 6 indeed provides partial protection from degeneration. However, we find at a biochemical level that Caspase- 6 is activated effectively only by Caspase- 3 but not other "upstream" caspases, prompting us to revisit the role of Caspase-3. In vitro, we show that genetic deletion of Caspase-3 is fully protective against sensory axon degeneration initiated by trophic factor withdrawal, but not injury-induced Wallerian degeneration, and we define a biochemical cascade from prosurvival Bcl2 family regulators to Caspase-9, then Caspase-3, and then Caspase-6. Only low levels of active Caspase-3 appear to be required, helping explain why its critical role has been obscured in prior studies. In vivo, Caspase-3 and Caspase-6-knockout mice show a delay in developmental pruning of retinocollicular axons, thereby implicating both Caspase-3 and Caspase-6 in axon degeneration that occurs as a part of normal development.

\section{Introduction}

Axon degeneration is a widespread mechanism to refine connectivity in the developing nervous system. Many axons are removed along with their cell bodies during the period of widespread, naturally occurring, neuronal cell death, often as a result of competition for limiting amounts of trophic factors like Nerve Growth Factor (Raff et al., 2002). Axons or axonal branches that overshoot intended targets can also be pruned back without cell body death, a process that may also be initiated by loss of trophic support or, alternatively, by pruning inducers like Semaphorins activating Neuropilins/Plexins (Cheng et al., 2001; Bagri et al., 2003; Low et al., 2008) or Brain-Derived Neurotrophic Factor activating p75NTR (Singh et al., 2008).

Developmental axon degeneration involves localized, branchspecific cytoskeletal destruction, with extensive blebbing and

Received June 25, 2012; revised Sept. 11, 2012; accepted Sept. 26, 2012.

Author contributions: D.J.S., R.M.W., R.N.H., and M.T.-L. designed research; D.J.S., R.M.W., T.M., D.K., K.S., and J.Y. performed research; D.D.M.O. and R.N.H. contributed unpublished reagents/analytic tools; D.J.S., R.N.H., R.M.W., T.M., D.D.M.O, and M.T.-L. wrote the paper.

This work was partially funded by NIH Grant R01 EY07025 (D.D.M.0).We thank Christine Pozniak and members of the Tessier-Lavigne laboratory for critical suggestions and commentary, Micah Steffek for help with protein purification, Merone Roose-Girma for help with generation of the Caspase- 9 knockout, and Nona Velarde for assistance in genotyping.

The authors declare no competing financial interests.

Correspondence should be addressed to Marc Tessier-Lavigne at his present address: Laboratory of Brain Development and Repair, The Rockefeller University, 1230 York Avenue, New York, NY 10065. E-mail: marct!@rockefeller.edu.

D. J. Simons's and J. Yang's present address: Laboratory of Brain Development and Repair, The Rockefeller University, 1230 York Avenue, New York, NY 10065

DOI:10.1523/JNEUROSCI.3012-12.2012

Copyright $\odot 2012$ the authors $\quad 0270-6474 / 12 / 3217540-14 \$ 15.00 / 0$ fragmentation that are reminiscent of the initial stages of cell body apoptosis. Despite these similarities, a role for caspases, the effector proteases of apoptosis, in axon degeneration was initially widely discounted owing to failure to detect caspase activation as well as a lack of protection by z-VAD-Fmk (a relatively pancaspase inhibitor), z-DEVD-Fmk (a more Caspase- 3 selective inhibitor), or Caspase-3 knockdown, manipulations that all protect cell bodies from degeneration (Finn et al., 2000; Saxena and Caroni, 2007). Their potential involvement was, however, revisited more recently with the findings that sensory or sympathetic axons lacking the apoptotic effector Bax (Nikolaev et al., 2009), expressing the anti-apoptotic regulator Bcl-Xl (Vohra et al., 2010), or treated with the caspase inhibitor Z-VEIDFmk (Nikolaev et al., 2009; Vohra et al., 2010) are protected from degeneration after NGF withdrawal. Z-VEID-Fmk also protects sympathetic axons from prodegenerative effects of myelin in vitro (Park et al., 2010). z-VEID-Fmk has been considered more selective for Caspase-6; together with the observation of Caspase- 6 activation in the axons and protection by siRNA-mediated knockdown of Caspase-6, this led to the suggestion that axon degeneration involves activation of Caspase-6 (Nikolaev et al., 2009; Vohra et al., 2010).

To extend these studies, we took a genetic and biochemical approach to define the contribution of Caspase- 6 to axon degeneration, and we report that genetic deletion of Caspase- 6 does provide partial protection against sensory axon degeneration elicited by NGF withdrawal, as has also recently been seen for degeneration of sympathetic axons triggered by NGF withdrawal or by myelin (Uribe et al., 2012). While studying how Caspase-6 is activated, however, we found, consistent with prior suggestions 
(Hirata et al., 1998; Slee et al., 1999; Walsh et al., 2008), that Caspase- 3 function is required to activate Caspase-6, leading us to revisit the role of Caspase- 3 in axon degeneration. Unexpectedly, we found that Caspase-3 plays an obligate role in axon degeneration following NGF withdrawal in vitro. Our data suggest that only small amounts of Caspase- 3 are necessary to fully process Caspase- 6 and initiate degeneration, providing an explanation for the lack of detection or appreciable inhibition seen in other studies (Finn et al., 2000; Plachta et al., 2007; Nikolaev et al., 2009). Our studies also implicate Caspases-3 and -6 in developmental axon pruning in vivo.

\section{Materials and Methods}

Mice. Wild-type mouse cultures were derived from CD-1 embryos, except in experiments involving mutant mice, where wild-type embryos came from the same mother as the knockout embryo. Wild-type embryos used for in utero electroporation experiments were from the C57BL/6 background. Mice null for Caspase-3 (Kuida et al., 1996) were provided by R. Flavell (Howard Hughes Medical Institute, Yale University, New Haven, CT). Mice null for Bax (Knudson et al., 1995) were obtained from The Jackson Laboratory. Caspase-6-null mice (Uribe et al., 2012) were provided by the CDHI, Cure Huntington's Disease Initiative. Mice null for Caspase-9 were generated using standard techniques to delete exon 6 containing the catalytic cysteine motif (QACGG). Two similar strategies to delete this catalytic motif have been employed to generate null alleles of Caspase-9 (Hakem et al., 1998; Kuida et al., 1998). We validated loss of Caspase- 9 expression in lysates from embryonic day (E) 12.5 spinal cord and embryonic fibroblasts (Fig. 5D, data not shown).

Antibodies and reagents. The following antibodies were used in this study: Cleaved Caspase-3 (1:100), Cleaved Caspase-9 (1:100), Total Caspase-3 (1: 500), Total Caspase-9 (1:500), Lamin A/C (1:500) (Cell Signaling Technology), Active Caspase-6 (1:100, BioVision), proCaspase-3 (pAb 06-735, mAb E87, 1:200-500, Millipore), TuJ1 (1:1000, Covance), Neurofilament-M (1: 1000; Covance), XIAP and c-IAP1 (1:500, R\&D Systems), c-IAP1 (1:1000, Imgenex), Actin (1:10,000, BD Biosciences), and NGF (25 $\mu \mathrm{g} / \mathrm{ml}$, Genentech). The following inhibitors were used: z-DEVD-Fmk (Enzo Life Sciences), ABT-737 (Abbott Laboratories, Genentech), and MV1 (Genentech).

Neuronal cultures. Dorsal Root Ganglion (DRG) explant and Campenot chamber cultures were as described previously (Nikolaev et al., 2009). For experiments involving physical injury, E12.5 DRG explants were grown for 2 days in culture in the presence of NGF followed by physical severing of proximal axons with a razor blade. Cultures were fixed and stained after $16 \mathrm{~h}$.

Immunochemistry. To detect caspase cleavage in axons, cultures were fixed for $10 \mathrm{~min}$ in $4 \%$ paraformaldehyde containing $10 \%$ sucrose and blocked for $1 \mathrm{~h}$ at room temperature in 5\% BSA/0.1\% Triton X-100. Primary antibody was incubated overnight at $1: 100$ in $3 \%$ BSA $/ 0.05 \%$ Triton X-100. The next day cultures were washed in PBS and incubated with secondary antibody (Alexa Fluor 568, 1:300) for $1 \mathrm{~h}$ at room temperature. To visualize axon morphology and degeneration, cultures were fixed in $4 \%$ paraformaldehyde and stained with the TuJ 1 antibody using standard techniques.

Isolation of axonal proteins. E12.5 DRG explants were on Poly-DLysine/Laminin in N3/F12 medium supplemented with $25 \mathrm{ng} / \mathrm{ml} \mathrm{NGF}$ and $1 \mu \mathrm{M}$ cytosine arabinoside. Following 7 days in culture, the explants were deprived of NGF by adding an anti-NGF function-blocking antibody for varying times. Explants were washed with HBSS, and the axons were isolated by removing the center of the explant containing the cell bodies (J.Y. and M.T.-L., unpublished observations). The remaining axons were lysed in buffer consisting of $150 \mathrm{~mm} \mathrm{NaCl}, 50 \mathrm{~mm}$ HEPES, $0.1 \%$ Triton X-100, and protease inhibitors (Roche), concentrated by precipitation with TCA, and resolved by SDS-PAGE. Protein content was normalized by immunoblotting with an antibody to TuJ1.

In vitro processing of zymogen caspase- 6 by active caspases. Active Caspase-3 and - 6 enzymes were purified in-house (Stanger et al., 2012) and used at the indicated concentrations. All other active caspases were purchased from Enzo Life Sciences and used at a concentration of 1.0 $\mathrm{U} / \mu \mathrm{l}$. In each assay, recombinant zymogen Caspase-6 (1 $\mu \mathrm{M})$ was incu- bated with active caspase enzyme at $37^{\circ} \mathrm{C}$ for $1 \mathrm{~h}$ (Caspase- 6 or -3 ) or $1.5 \mathrm{~h}$ (Caspases- $1,-2,-4,-5,-7,-8,-9$, and -10). Long incubation periods were used in these end point assays to detect any zymogen processing mediated by the active caspases. The buffer used for Caspases-2, -3, -4, -6, and -7 is (in mM): 50 HEPES, pH 7.2, $5 \mathrm{MgSO}_{4}, 1 \mathrm{GSH}, 0.5$ EGTA, and $0.01 \%$ Triton X-100. The buffer used for Caspases- $1,-5,-8,-9$, and -10 is: 50 mм HEPES, pH 7.2, $50 \mathrm{~mm} \mathrm{NaCl}, 0.8 \mathrm{~m} \mathrm{Na}$-Citrate, 1 mm EDTA, and $10 \mathrm{~mm}$ DTT. Samples were analyzed by SDS-PAGE $(10-20 \%$ Trisglycine), and the gels were scanned on an Odyssey infrared scanner and quantified using Odyssey software. Under these conditions, all enzymes were verified in fluorogenic assays to be active in processing their specific tetrapeptide-AMC substrates (data not shown).

GFP labeling of retinal ganglion cell populations by in utero electroporation. Retinal ganglion cell (RGC) populations were labeled in utero via electroporation of a CAGGS promoter-based GFP expression plasmid into RGC precursor cells as described previously (Garcia-Frigola et al., 2007). Caspase-3, Caspase-6, or C56BL/6 control time-pregnant females were anesthetized with $2 \%$ isoflurane at embryonic gestation day 13 and secured to a heating pad, and their uterine horns were exposed by incision through the abdominal dermis and body wall muscle. The right eye of individual embryos were injected through the uterine wall using a fine glass capillary needle (Humagen, Origio) connected to a pressure injector (Picospritzer, Parker) calibrated to deliver $0.5 \mu \mathrm{l}$ of $1 \mu \mathrm{g} / \mu \mathrm{l}$ plasmid DNA, and then electroporated with a series of five square electrical pulses (40 V, $50 \mathrm{~ms}, 450 \mathrm{~ms}$ interval) delivered through $3 \mathrm{~mm}$ diameter paddle electrodes (Tweezertrode, BTX). Postelectroporation, the uterine horns were placed back into the abdominal cavity, the incision was closed by suture, and the females were treated with an analgesic $(0.1 \mathrm{mg} / \mathrm{kg} \mathrm{Bu}-$ prenorphine) before recovery from anesthesia. Roughly 6 days postsurgery, electroporated pups were born expressing GFP in RGC populations located primarily in the central region of the retina (Garcia-Frigola et al., 2007).

Quantification of GFP-labeled RGC developmental axon pruning within the superior colliculus. At indicated developmental ages, electroporated pups were sacrificed, brains were fixed overnight in $4 \%$ paraformaldehyde/PBS, and tail samples were collected to confirm genotype of the individual. Postfixation, brains were immersed in PBS, stereotactically positioned under an objective lens $(10 \times$ numerical aperture 0.6 , Olympus) and a volume $\sim 1 \times 1 \times 0.4 \mathrm{~mm}$ of the left superior colliculus imaged en bloc by two-photon microscopy: $910 \mathrm{~nm}$ pulsed laser (Spectra-Physics Mai Tai DeepSee laser, Newport), 510/60 nm bandpass filter (Chroma Technology), and two-photon laser scanning microscope with $x-y$ resolution, $1.1 \mu \mathrm{m} /$ pixel (Ultima IV, Prairie Technologies). The extent of axon pruning was estimated by counting the number of GFPexpressing axons within $100 \mu \mathrm{m}$ of the posterior edge of the imaged field of view. The relative size of the termination zone was estimated by measuring the width at half maximum of the summed GFP + pixel distribution along the anterior-posterior axis.

DiI labeling of retinal ganglion cell axons. Experiments involving DiI labeling were performed as described previously (McLaughlin et al., 2003; Nikolaev et al., 2009).

\section{Results}

\section{Loss of Caspase-6 provides partial protection against NGF deprivation}

We began by examining genetically the role of Caspase- 6 in sensory axon degeneration in vitro following withdrawal of the trophic factor NGF (along with addition of anti-NGF antibody to eliminate all residual trophic factor-a combination referred to below as "NGF-deprivation"). In this paradigm, the inhibitor compound z-VEID-Fmk, whose sequence derives from the Caspase-6 cleavage site in Lamin A, has been shown to protect sensory and sympathetic axons from degeneration after trophic deprivation (Nikolaev et al., 2009; Vohra et al., 2010) and to protect sympathetic axons from the prodegenerative effects of myelin in vitro (Park et al., 2010). DRG neurons from E12.5 wild-type or Caspase-6-knockout embryos were cultured in 
A

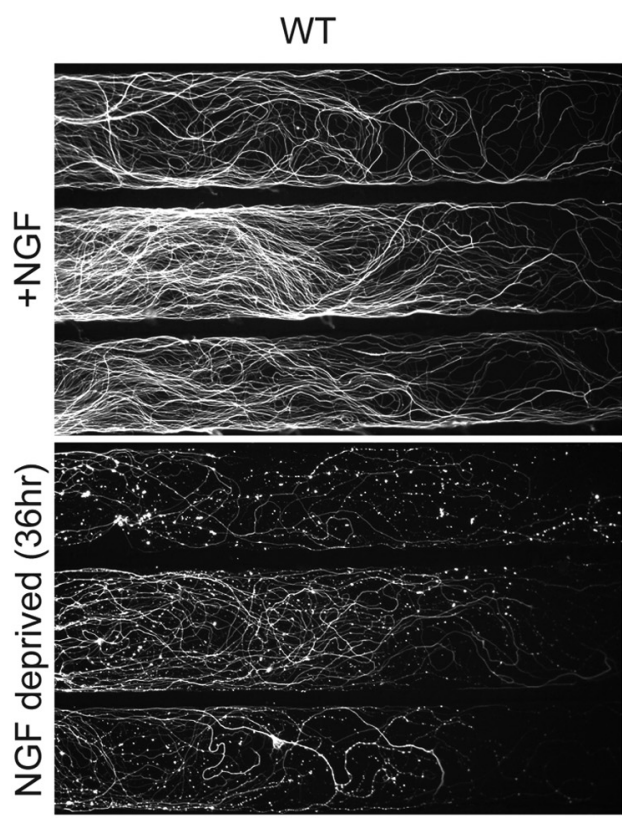

B

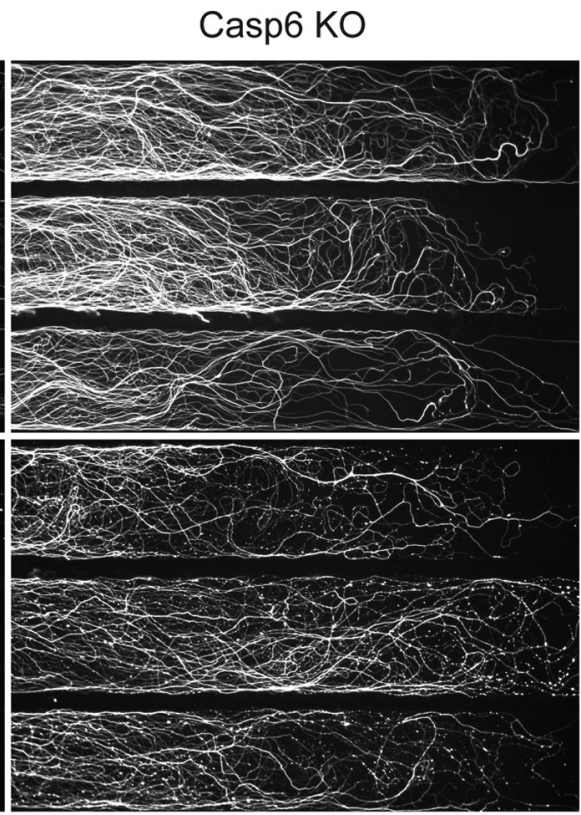

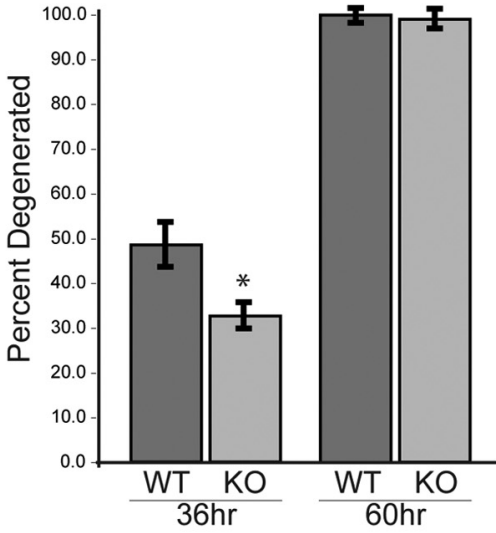

Figure 1. Loss of Caspase-6 partially protects against degeneration induced by NGF withdrawal. $\boldsymbol{A}$, Wild-type (WT) and Caspase-6-knockout (K0) DRGs were cultured in Campenot chambers for 7 days in $50 \mathrm{ng} / \mathrm{ml} \mathrm{NGF}$ and subsequently deprived of NGF for 36 and $60 \mathrm{~h}$ by washing out NGF and adding a function blocking anti-NGF antibody. Representative images of three rows of axons per chamber, per condition, in the presence or absence of NGF at $36 \mathrm{~h} . \boldsymbol{B}$, Axon degeneration was quantified as the percent of total axons with fragmented staining of $\beta$ III-Tubulin (TuJ1) across all wells of the chamber. To exclude the possibility that loss of Caspase- 6 (or other mutations used in this study) affects the number of axons that traverse the grease barrier, we quantified the number of axons in the control ( + NGF) side of each chamber and found no significant difference (data not shown). Each chamber derived from a unique embryo. $n=11$ chambers per genotype; ${ }^{*} p=0.0130$ at $36 \mathrm{~h}$ time point, Student's $t$ test.

Campenot chambers with NGF. In this paradigm, axons grow for 7 days and travel under a grease barrier that allows independent manipulation of the somatic and axonal compartments (Campenot et al., 1991). Upon NGF withdrawal of the axonal compartment, axons degenerate slowly with pronounced fragmentation of axons visualized by $\beta$ III Tubulin immunohistochemistry (detected with TuJ1 antibody) visible within $36 \mathrm{~h}$. We assayed protection from the prodegenerative effects of NGF withdrawal in wild-type and Caspase-6-knockout axons at this $36 \mathrm{~h}$ time point and observed a significant though incomplete protective effect in Caspase-6-knockout axons (Fig. 1), confirming involvement of Caspase- 6 in axon degeneration in this paradigm, as has also recently been seen for degeneration of sympathetic axons triggered by NGF withdrawal or exposure to myelin (Uribe et al., 2012). However, loss of Caspase- 6 was only transiently protective, as the magnitude of axon degeneration assayed at $60 \mathrm{~h}$ is equivalent in the two genotypes (Fig. $1 B$ ). Previous work from our laboratory has shown that Bax-knockout sensory axons are protected against NGF withdrawal at all time points examined up to $60 \mathrm{~h}$ (Nikolaev et al., 2009). This prompted us to investigate the role of other caspases in axon degeneration to determine whether any acted redundantly with Caspase- 6 , and also to determine the mechanism of activation of Caspase- 6 .

\section{Caspase- 6 is processed by Caspase- 3}

Cleavage of cellular substrates during apoptosis is achieved by three effector caspases, Caspase-3, -6, and -7. Mature catalytically active effector caspases are processed from their zymogen precursors by removal of a short prodomain and cleavage between the large and small subunits by initiator caspases. We began by studying the processing and activation of Caspase- 6 as an entry point to discovering other caspases that function during axon degener- ation. Zymogen Caspase- 6 is unique among effector caspases due to the presence of a linker region between the large (p18) and small (p11) subunits, thereby requiring two distinct cleavage events to liberate p18 and p11 (Fig. 2A).

To determine how Caspase- 6 is processed, we developed an in vitro zymogen conversion assay in which full-length Caspase- 6 is incubated with recombinant active variants of each mammalian caspase. The activity of each recombinant caspase was verified by coincubation with its cognate fluorogenic substrate (data not shown). To exclude the contribution of autoprocessing, the fulllength Caspase- 6 used in our assays contained an active site C163A mutation that abolishes catalytic activity (hereafter referred to as zymogen Caspase-6). Caspases-3 and -7 can be processed by either of the two initiator caspases as a result of death receptor activation (Caspase-8) or activation of the mitochondrial pathway (Caspase9). Unexpectedly, we found that Caspases- 8 and -9 could not process recombinant zymogen Caspase-6 efficiently, nor could Caspase-1, which has previously been suggested as an activator of Caspase- 6 (Guo et al., 2006) (Fig. 2 B). Instead, of the panel of active caspases that we screened, only Caspase- 3 could process and activate Caspase- 6 effectively at low-nanomolar concentrations, presumed to be physiological. Processing of Caspase- 6 by Caspase- 3 at the three cleavage sites (Asp23, Asp179, Asp193) occurred at subnanomolar concentrations and in a dose-dependent manner (Fig. 2C,D). In sharp contrast, active Caspase- 6 only processes efficiently the prodomain of zymogen Caspase-6 (at Asp23), and to a much lesser extent the C terminus (Asp193) of the linker region (Fig. 2E, F), with no detectable cleavage at Asp179. We further confirmed these results by generating a D23A/D179A zymogen Caspase-6, which is processed weakly by active Caspase- 6 but not Caspase-3 (Fig. $2 G-I$ ). In 
A

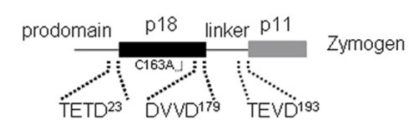

C

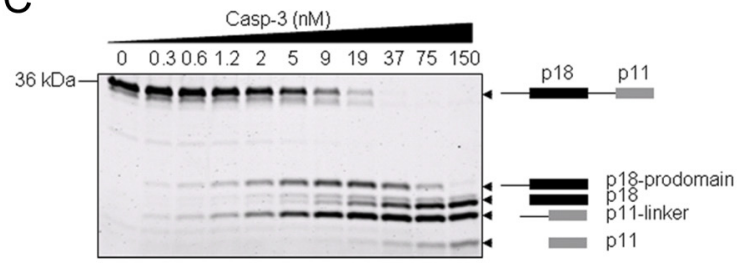

D

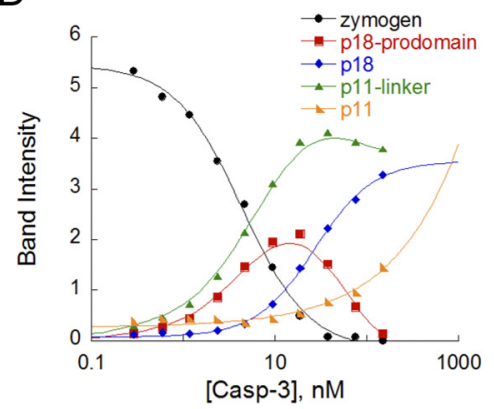

G
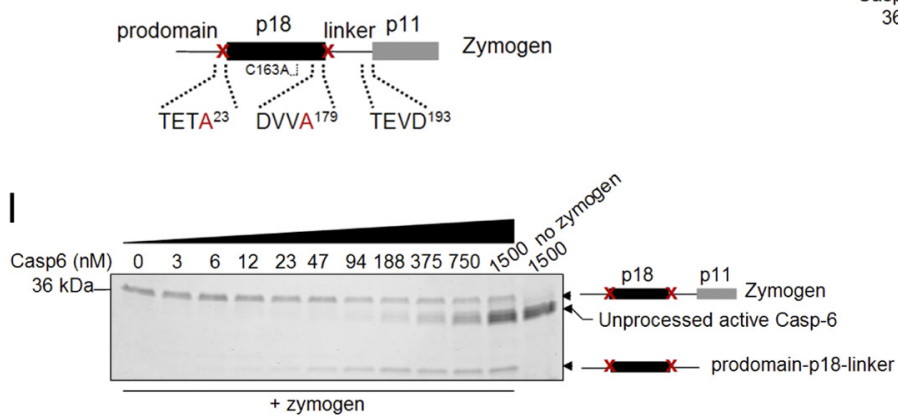

B

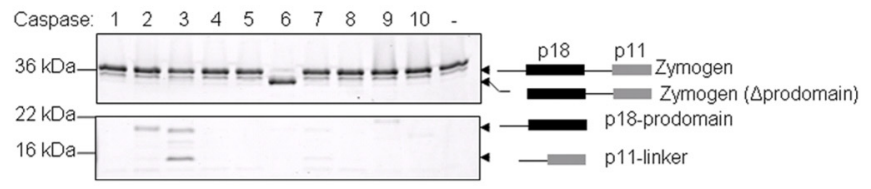

E

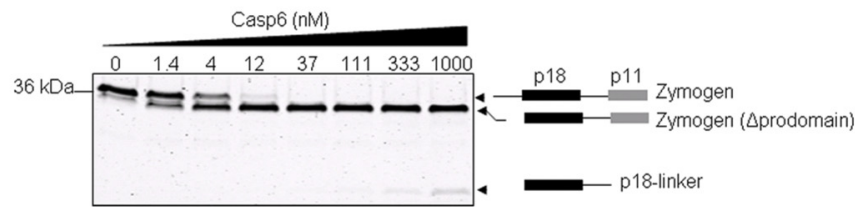

F
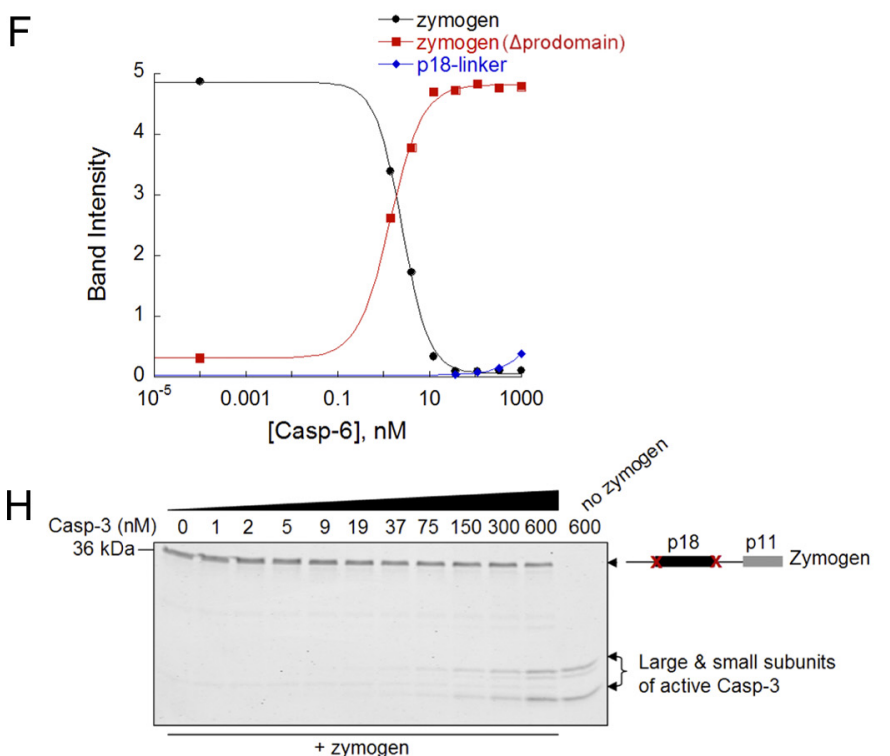

Figure 2. Processing of zymogen Caspase- 6 by active Caspases-3 and -6. A, Domain organization of zymogen Caspase- 6 highlighting the catalytic C163A mutation and the three cleavage sites. $B$, Processing of zymogen Caspase- 6 by a panel of catalytically active caspase family members showing different extents of cleavage by Caspases-3 and -6 . The band observed in lane 2 corresponds to the large subunit of Caspase-2.C, D, Zymogen Caspase-6 is fully processed by active Caspase-3 in a concentration-dependent manner. E, $\boldsymbol{F}$, Zymogen Caspase- 6 is efficiently processed in trans only at its prodomain by active Caspase-6. The cleavage products from processing by Caspase-3 (Casp-3) or Caspase-6 (Casp-6) were confirmed by N-terminal sequencing (data not shown) and quantified, and they are plotted in $\boldsymbol{D}$ and $\boldsymbol{F}$, respectively. $\boldsymbol{G}$, Domain organization of zymogen Caspase-6 highlighting the catalytic C163A, and D23A/D179A mutations. A point mutation (D186A) was also introduced to prevent potential cleavage in the middle of the linker region. $\boldsymbol{H}, \boldsymbol{I}$, Zymogen Caspase-6/D23A /D179A mutant is processed weakly by active Caspase-6 but not Caspase-3.

all cases, the identity of the processed species was confirmed by $\mathrm{N}$-terminal protein sequencing (data not shown).

Taken together, our data suggest that Caspase-3, but not Caspases- 6 , -8 , or -9 , fully processes zymogen Caspase- 6 , and that Caspase-3 processing of zymogen Caspase-6 at Asp179 is necessary for Caspase- 6 maturation, enabling subsequent processing at Asp23 followed by Asp193 to generate fully active Caspase-6. Caspase- 3 shows a preference for cleavage of sequences with the general DXXD consensus motif. This may explain why Caspase-3 favors Asp179 as its first cleavage site on zymogen Caspase-6 followed by Asp23. On the other hand, Caspase- 6 shows a preference for cleavage of peptides with a XEXD consensus sequence, consistent with its in trans processing mechanism of zymogen Caspase-6 at Asp23 first followed by Asp193 with little or no cleavage observed at Asp179 (Fig. 2E, F). The inefficient trans cleavage at Asp193 may be explained by the fact that TEVD193, which forms a $\beta$-strand, is buried in the active site of the zymogen, rendering it inaccessible for cleavage (Wang et al., 2010; Stanger et al., 2012).

\section{Caspase- 3 is required for axon degeneration following NGF withdrawal}

The finding that only Caspase-3, but not other caspases tested, activates Caspase- 6 effectively prompted us to revisit whether Caspase- 3 might also contribute to the axon degeneration program. Multiple studies using the peptide inhibitor z-DEVD-Fmk, whose sequence derives from the Caspase- 3 cleavage site in PARP1, found that it did not protect DRG axons from degeneration initiated by NGF withdrawal or axotomy (Finn et al., 2000; Nikolaev et al., 2009; Schoenmann et al., 2010). In contrast, and 
strikingly, when we cultured DRG neurons from Caspase-3-null embryos we found that loss of Caspase-3 was fully protective against axon degeneration initiated by NGF withdrawal in both DRG explants (after 2 days in culture) and in Campenot chambers (after 7 days in culture) at all time points examined (Fig. $3 A, B)$. In explant cultures we examined axon degeneration at $24 \mathrm{~h}$, well past the $16 \mathrm{~h}$ time point typically assayed. At this time all of the wild-type axons had degenerated, while there was no evidence of fragmentation in the knockout cultures, as assessed by TuJ1 immunohistochemistry (IHC) (Fig. 3A). Similarly, while wild-type axons in Campenot chambers were largely degenerated at the $36 \mathrm{~h}$ time point, axons from the Caspase-3-knockout were protected through the $60 \mathrm{~h}$ time point as shown (Fig. $3 B, C$ ). In addition, explants grown for 7 days (but not in Campenot chambers) were also fully protected in the Caspase-3 knockout (data not shown). The magnitude and duration of axon protection seen in the Caspase-3 knockout is equivalent to what we have previously observed in Bax-knockout neurons (Nikolaev et al., 2009).

The discrepancy between our knockout data and previous results using z-DEVD-Fmk led us to investigate the protective effect of this compound more fully. We found that, while z-DEVD-Fmk does not protect NGF-deprived axons from wildtype neurons in Campenot chambers, it does protect axons from Caspase-3 heterozygous littermates when assayed at the $36 \mathrm{~h}$ time point (Fig. 3D). However the protection endowed on heterozygous axons by z-DEVD-Fmk was only transient, as the axons were fully degenerated by the $60 \mathrm{~h}$ time point (Fig. 3E). Interestingly, whereas z-DEVD-Fmk protected axons when the dosage of Caspase- 3 was halved, simply doubling the concentration of the compound to which wild-type neurons were exposed did not produce a protective effect (data not shown; see Discussion).

We next used the Caspase-3 knockout to determine whether our biochemical data showing that Caspase- 3 activates Caspase- 6 had an in vivo counterpart. Indeed, we found that axonal staining for active Caspase-6 in axons was eliminated in DRG explants from Caspase-3 knockout neurons deprived of NGF (Fig. 3F).

Previous results indicated that the z-DEVD-Fmk compound does not protect against axotomy-induced Wallerian degeneration (Finn et al., 2000). We revisited this experiment in light of our surprising finding that the Caspase-3 knockout, but not z-DEVD-Fmk, protects against NGF withdrawal. Genetic loss of Caspase-3 or Caspase-6 also did not protect against Wallerian degeneration in E12.5 DRGs (Fig. 3G, data not shown), consistent with previous results as well as genetic data in mutants lacking both Bax and Bak (Whitmore et al., 2003). Our results therefore provide additional support for the view that caspases do not contribute to Wallerian degeneration. We also tested the response of Caspase-3-knockout axons in Campenot chambers to the tubulin depolymerizing chemotherapeutic agent vincristine, and failed to observe a protection against degeneration (Fig. $3 H$ ). Together, these data suggest that Caspase- 3 participates in the developmental response of axons to NGF withdrawal but not to these two nondevelopmental, injury-inducing stimuli.

\section{Activation of Caspase-3 in degenerating axons}

Our finding that Caspase-3-knockout axons are fully protected from degeneration next led us to reexamine the data on activation of Caspase-3 in these axons. Biochemical activation of Caspase-3 from its zymogen precursor requires cleavage at the inter-subunit linker between the large and small subunits. This cleavage is an obligate event in the maturation of Caspase- 3 , and therefore detection of this cleavage event is commonly used as a surrogate for “activated" Caspase-3 (Walters et al., 2009). Previous studies have produced conflicting results on the ability to detect cleaved Caspase-3 in degenerating axons, leading to a widely held notion that axon degeneration is Caspase- 3 independent (Saxena and Caroni, 2007). Some of this discrepancy appears to relate to the use of different experimental conditions. For example, one study did not find cleaved Caspase-3 immunoreactivity in sensory axons deprived selectively in long-term cultures in Campenot chambers, but it did observe cleaved Caspase- 3 in axons when dissociated neurons in short term culture were deprived (which involved deprivation of both axons and their cell bodies) (Finn et al., 2000). Two other studies observed cleaved Caspase-3 in sensory axons following global NGF withdrawal (Kouroku et al., 1998; Schoenmann et al., 2010), although they did not report data from local deprivation. A number of other cell types have been used to examine the subcellular localization of cleaved Caspase-3. Cleavage of Caspase- 3 is not detected in axons of differentiated embryonic stem cells induced to degenerate by p75(NTR) overexpression (Plachta et al., 2007), while it is detected in cortical axons degenerating after traumatic brain injury (Dikranian et al., 2008). The lack of a consistent trend in the literature as well as our finding that Caspase- 3 is required for degeneration in vitro prompted us to revisit whether Caspase- 3 is cleaved in degenerating axons in our system.

We first examined the expression of the unprocessed (uncleaved) pro-Caspase-3 zymogen in axons by IHC. Previous analysis by IHC revealed staining in cell bodies but not axons (Nikolaev et al., 2009). However, when we compared the staining in DRG explants from wild-type and Caspase-3-knockout mice, we found that the cell body staining observed with several antibodies did not disappear in the knockout, suggesting that these antibodies are not suitable for specific detection of pro-Caspase-3 by IHC (Fig. $4 A$, data not shown). We therefore sought an alternative approach and took advantage of a novel method to isolate axonal material separately from cell bodies (J. Yang et al., manuscript in preparation), which we probed by Western blotting using these same antibodies. We found that pro-Caspase- 3 is, in fact, abundant in axons; the signal was specific since it disappears in material from the Caspase-3 knockout (Figs. 4B, 5A). Thus, prior analysis was misleading, and the immature form of Caspase- 3 is, in fact, present in DRG axons.

We next asked whether pro-Caspase-3 is cleaved during NGF withdrawal. In a first set of experiments, we cultured mouse E12.5 DRGs in Campenot chambers (for 7 days) followed by NGF withdrawal and stained them using a neo-epitope antibody for cleaved Caspase-3. We examined multiple time points before overt fragmentation (assessed by TuJ1 antibody) and found that the staining pattern of cleaved Caspase- 3 was variable, with a few axons strongly positive, but most other, often adjacent axons, exhibited little detectable cleaved Caspase-3 staining (Fig. 4C). Staining of parallel cultures from Caspase-3-knockout neurons allowed us to differentiate between signal and background and confirmed a lack of appreciable and consistent immunoreactivity to cleaved Caspase- 3 in degenerating axons (Fig. 4C). The same result was obtained when we examined the axons from explants that had been cultured for 7 days, but not in Campenot chambers, and were deprived of NGF (in these cultures, both axons and cell bodies are deprived): again, little or in many cases no immunoreactivity to cleaved Caspase- 3 was observed (Fig. 4D). In contrast, when these 7 day cultures were treated with the general proapoptotic stimulus staurosporine $(1 \mu \mathrm{M})$ for just $3 \mathrm{~h}$, strong axonal staining for cleaved Casapse- 3 was observed (Fig. 4D), consistent with the presence of pro-Caspase- 3 documented above. 
A

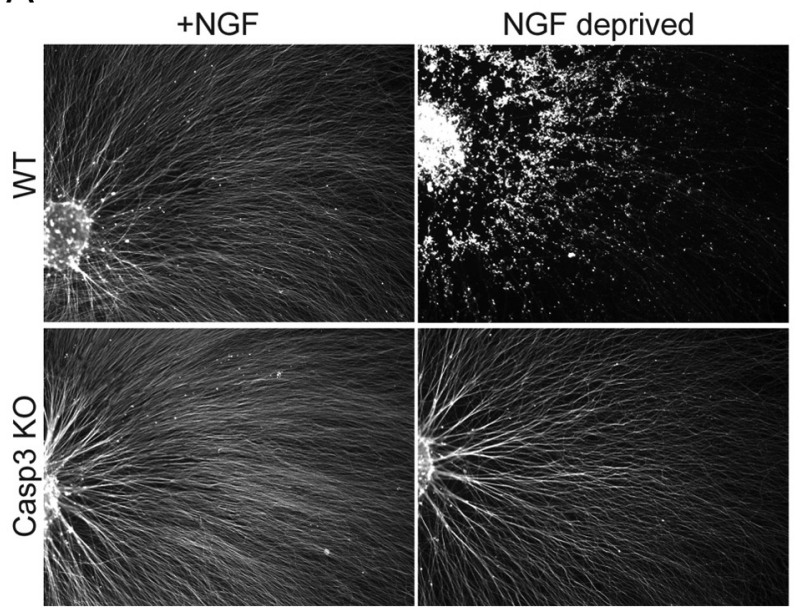

B

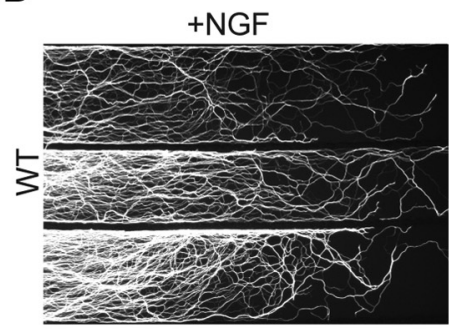

+ NGF

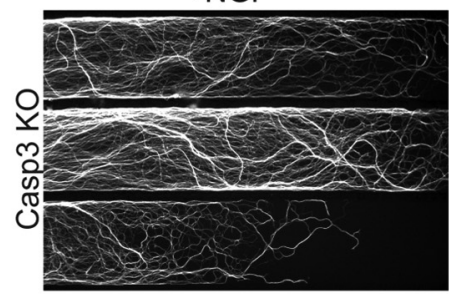

NGF deprived (36hr)

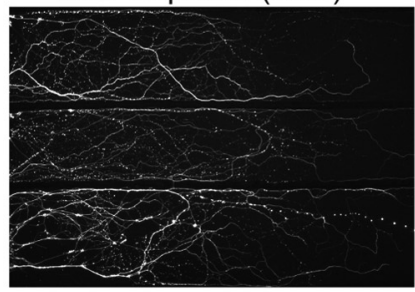

NGF deprived (60hr)

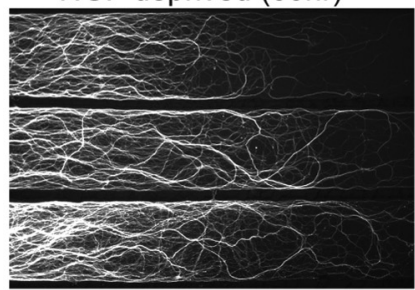

C

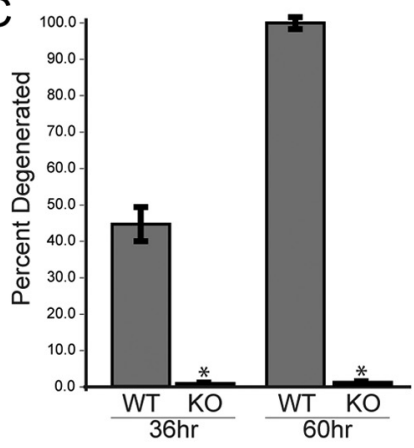

$\mathrm{F}$

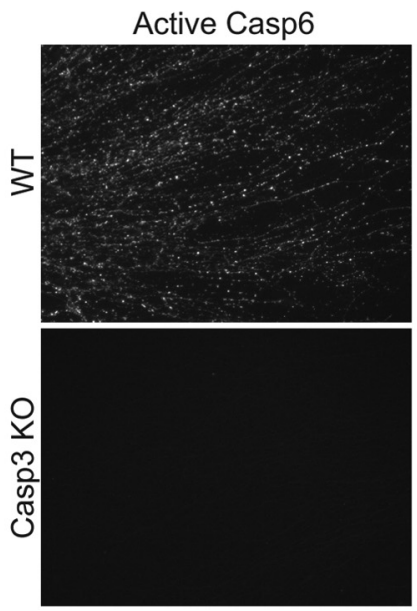

D

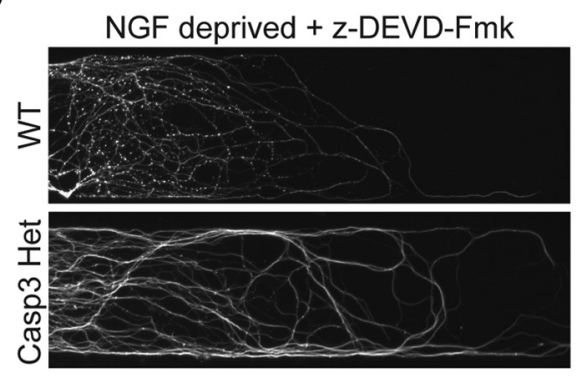

$G$

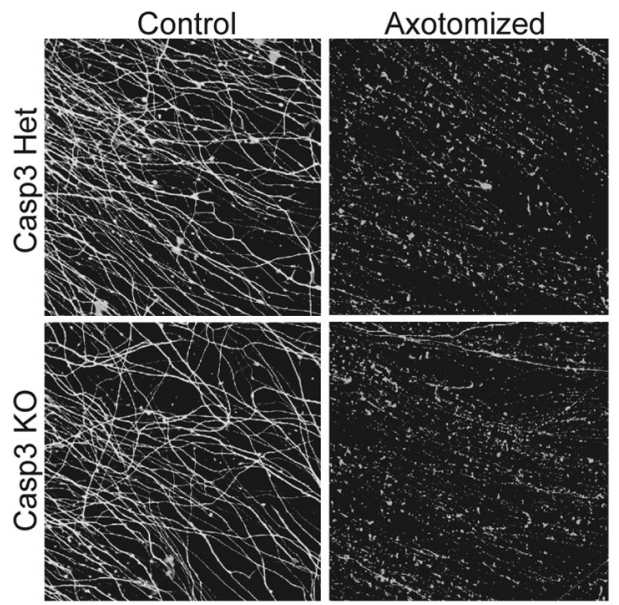

E

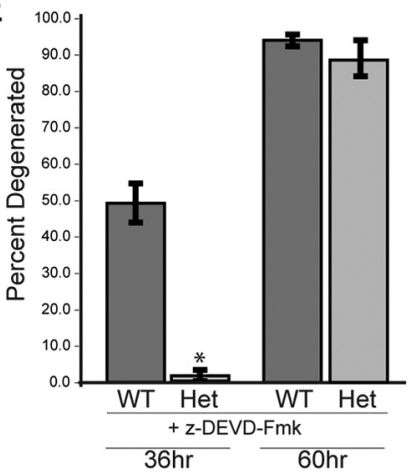

$\mathrm{H}$

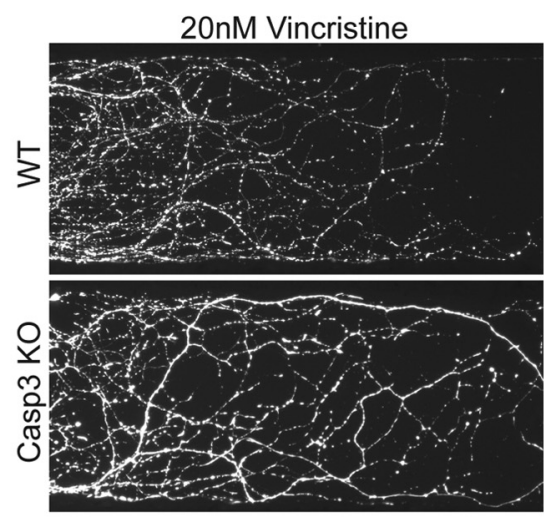

Figure 3. Caspase-3 is required for axon degeneration following NGF withdrawal. A, E12.5 DRG explants from wild-type (WT) and Caspase-3 knockout (K0) mice were cultured for 2 days and subsequently deprived of NGF for $24 \mathrm{~h}$ using a function blocking antibody. WT explants had completely degenerated while we observed no apparent degeneration in the Caspase-3 KO. B, Identical findings were seen in Campenot chambers. Representative images are shown of three rows of axons per genotype. WT degeneration is shown after $36 \mathrm{~h}$ in anti-NGF, while the Caspase-3 KO cultures are shown following $60 \mathrm{~h}$ in anti-NGF to illustrate the magnitude of the protection observed. C, Quantification of phenotype from B. Axons are significantly protected from NGF deprivation at both 36 and $60 \mathrm{~h} ; n=6$ Campenot chambers per genotype per time; ${ }^{*} p<0.001$ at each time point, Student's $t$ test. $\boldsymbol{D}$, We observed protection against anti-NGF in Campenot chamber cultures treated with $30 \mu \mathrm{m} \mathrm{Z-DEVD-Fmk} \mathrm{when} \mathrm{the} \mathrm{axons} \mathrm{were} \mathrm{from} \mathrm{Caspase-3} \mathrm{heterozygous} \mathrm{(Het)} \mathrm{mice,} \mathrm{whereas} \mathrm{no} \mathrm{protective} \mathrm{effect}$ was observed in WT axons. Representative images from the $36 \mathrm{~h}$ time point. $\boldsymbol{E}$, Quantification of $\boldsymbol{D}$. Significant protection is observed at the $36 \mathrm{~h}$ time point ( $p<0.001$, Student's $t$ test, $n=5$ per condition) but not at $60 \mathrm{~h}$. Axons are visualized by TuJ1 immunoreactivity $(\boldsymbol{A}, \boldsymbol{B}, \boldsymbol{D}) . \boldsymbol{F}$, Cleavage of Caspase- 6 is visualized by immunostaining in WT explants deprived of NGF for $12 \mathrm{~h}$. This cleavage is eliminated in Caspase-3 knockout explants. $G$, No apparent protection from injury-induced Wallerian degeneration of axons was observed in Caspase-3 knockout explants following physical severing of proximal axons in vitro. Caspase-6 knockout explants were also not protected (data not shown). $\boldsymbol{H}$, Similarly, loss of (aspase-3 does not protect axons in Campenot chambers from degeneration elicited by the chemotherapeutic agent vincristine. 


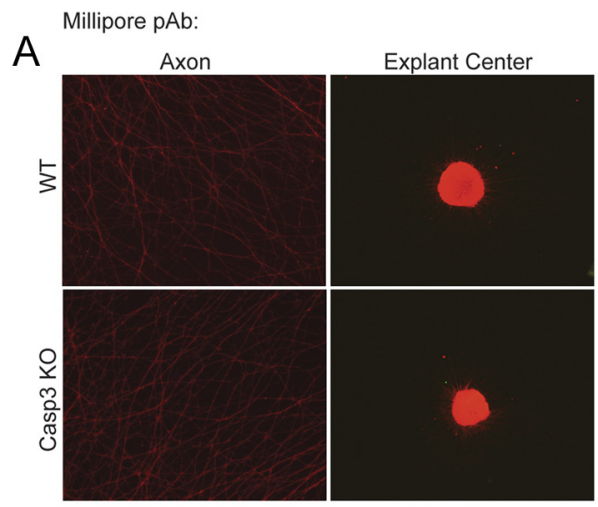

C Campenot chamber
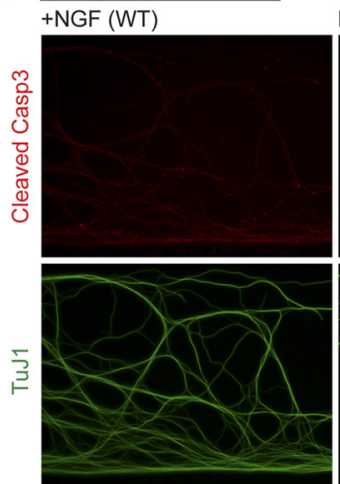

D Explant

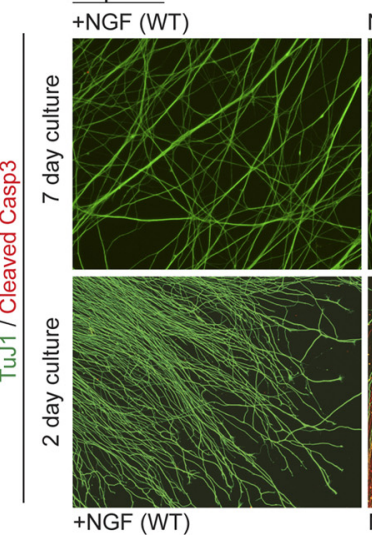

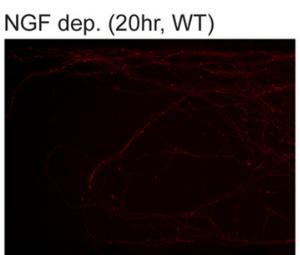

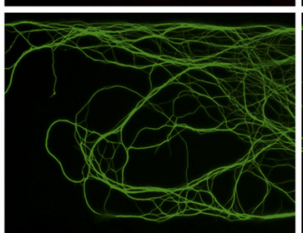

NGF dep. (24hr, WT)

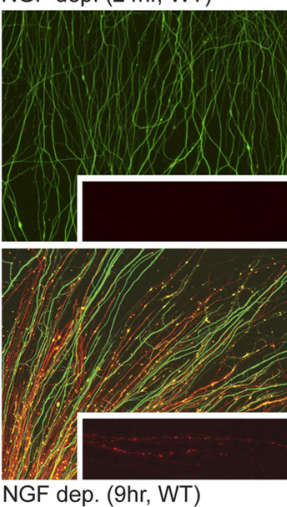

B

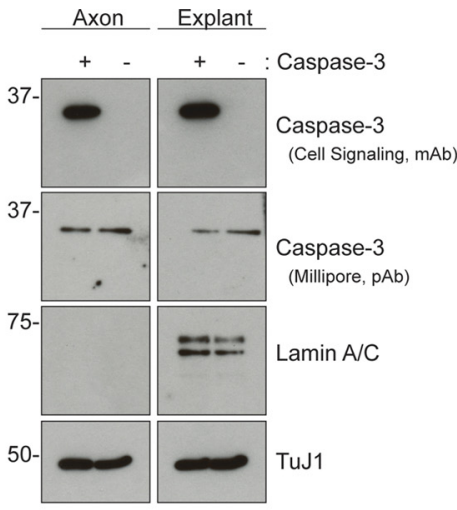

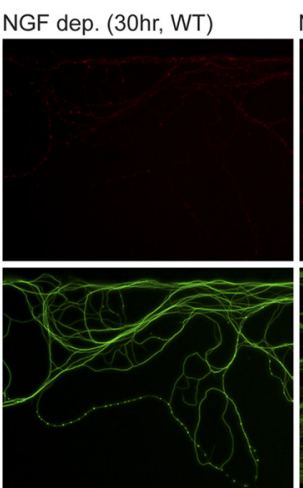

NGF dep. (30hr, Casp3 KO)

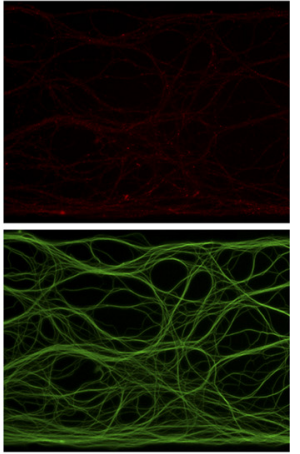

NGF dep. (45hr, WT)

Staurosporine (3hr, WT)
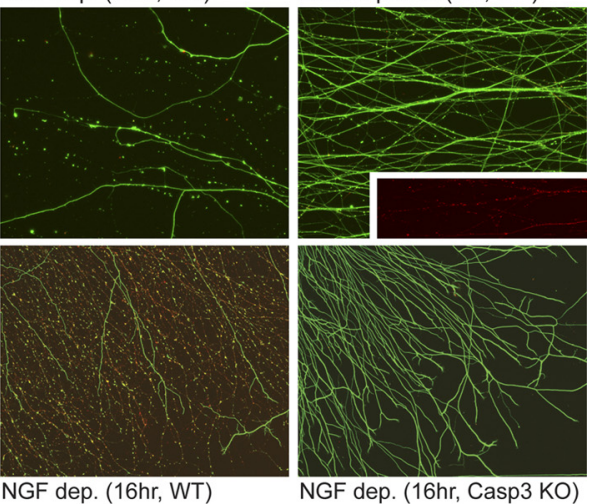

Figure 4. Detection of cleaved Caspase-3 in NGF-deprived sensory axons. A, Wild-type (WT) and Caspase-3-knockout (KO) DRG explants were cultured from E12.5 embryos in the presence of NGF for 2 days, fixed, and stained with either of two antibodies to pro-Caspase-3, a polyclonal (Millipore, catalog no. 06-735) and a monoclonal (Millipore, clone E87; data not shown). While diffuse axonal staining was observed, in neither case did this immunoreactivity disappear in the Caspase-3 knockout. B. Parallel cultures were lysed, either as full explants or when the cell bodies have been mechanically removed (see Materials and Methods, referred to as "Axon"). The purity of axonal protein preparations was confirmed by immunoblotting with the nuclear marker Lamin A/C. The Millipore polyclonal antibody detected a single band at the rough molecular weight of Caspase-3; however, this band did not disappear in the knockout. By contrast, the Cell Signaling Technology antibody (mAb 8G10) detected a band that disappeared in the knockout, indicating both the presence of pro-Caspase-3 and the specificity of this antibody, which was therefore used to detect activation of Caspase-3 in Figure 5 A. Several attempts to detect a signal by immunoblotting with mAb E87 were unsuccessful (data not shown), so, like the polyclonal antibody, E87 was not used for other experiments. C, WT axons were grown in Campenot chambers and subsequently deprived of NGF for varying times. Axons were fixed and stained with a neo-epitope antibody directed against the Asp175 cleavage site in Caspase-3. Staining for cleaved Caspase-3 is only seen in a subset of axons. Stainings were performed before overt TuJ1 fragmentation, here at $30 \mathrm{~h}$ following NGF withdrawal. In our experiments, fragmentation assessed by TuJ1 antibody in Campenot chambers begins rapidly after the $30 \mathrm{~h}$ time point, and axons are often $40-50 \%$ fragmented by $36 \mathrm{~h}$ (see Figs. 1B,3B).D, DRG explants were grown for 2 or 7 days, and both cell bodies and axons were deprived of NGF for the indicated times. Axons from 7 day cultures took considerably longer to fragment, as assayed by TuJ1 staining. Similar to Campenot chambers grown for the same 7 day period, cleaved Caspase-3 staining was not readily detected in 7 day explant cultures deprived of NGF, but was readily detected when those same cultures were exposed to staurosporine ( $3 \mathrm{~h}, 1 \mu \mathrm{m}$, top). In contrast, in 2 day cultures strong and uniform cleaved Caspase-3 staining develops over time in and is eliminated in Caspase-3 knockout explants (bottom). Inset: Higher magnification examples of the punctate appearance of cleaved Caspase-3.

These results raised the possibility that, in these long-term cultures, either Caspase-3 is not cleaved in the axons during NGF deprivation, or that it is cleaved but the amount generated is below the detection level by IHC. Consistent with the latter possibility, we observed time-dependent cleavage of
Caspase- 3 in axonal preparations from 7 day cultures by Western blotting (Fig. 5A). Thus, Caspase- 3 is, in fact, cleaved in these cultures, but importantly this can be clearly seen only by Western blotting, which is therefore a more sensitive means of detection than IHC. Moreover, the fact that staurosporine 
A

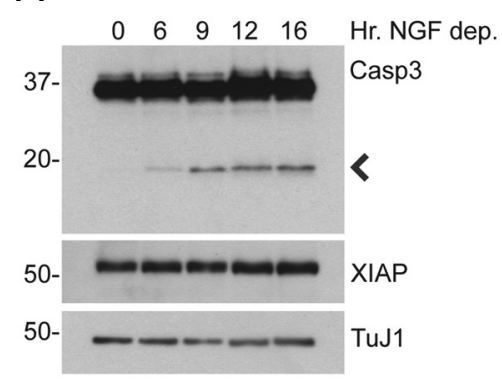

B

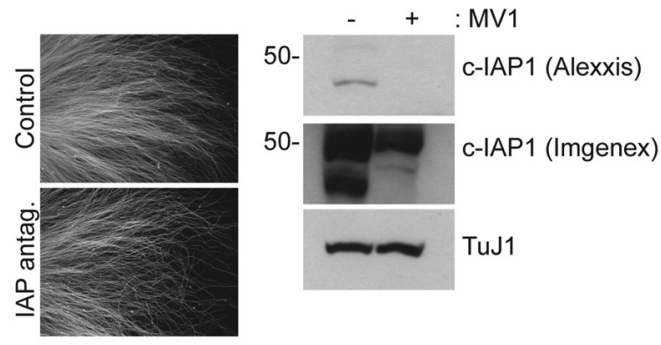

C

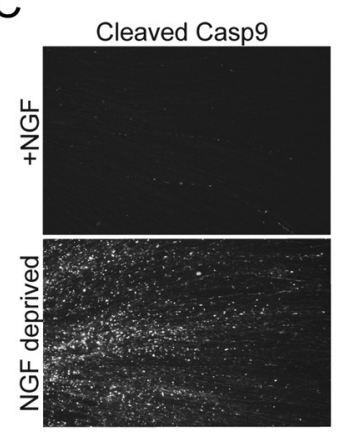

F
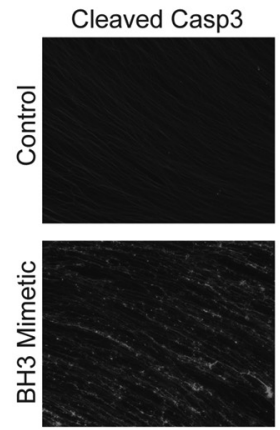

D
E
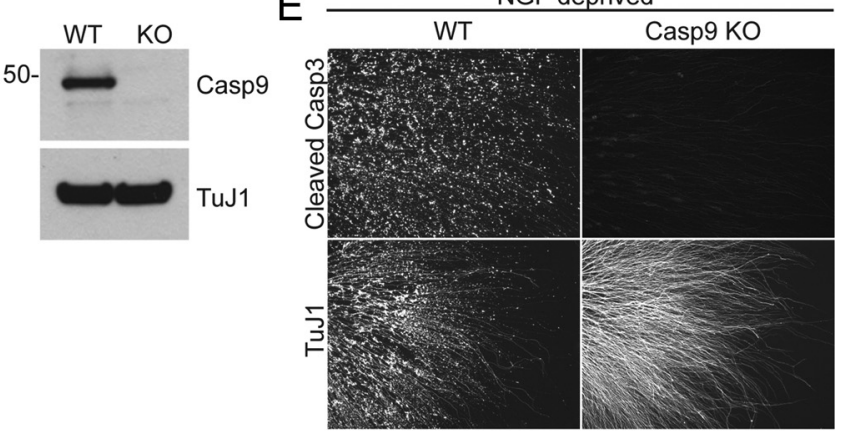

G

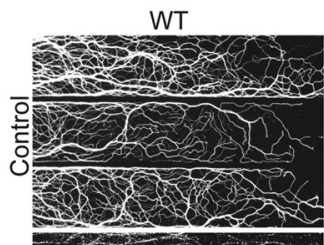

Bax KO

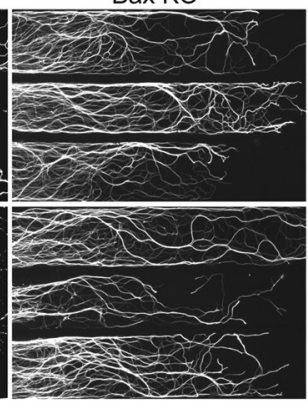

Casp3 KO

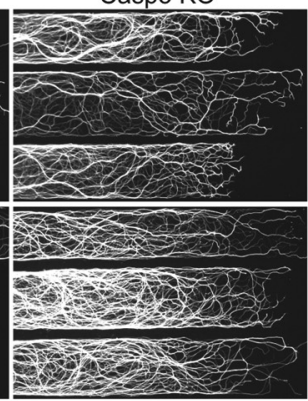

$\mathrm{H}$
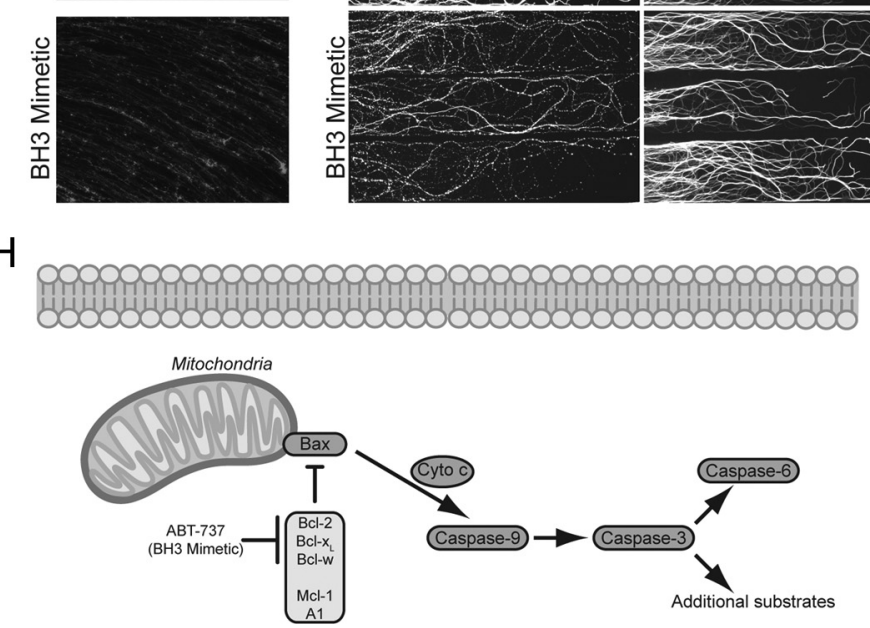

Figure 5. Cleavage of Caspase-3 is downstream of Caspase- 9 and the anti-apoptotic BCl-2 family. A, Western blot analysis of isolated axonal protein following a time course of NGF withdrawal. Caspase- 3 is processed from its immature zymogen form into its smaller, active subunit, marked with an arrow. During this period we do not observe a change in XIAP levels. $\boldsymbol{B}$, Wild-type (WT) DRG explants were incubated with an IAP antagonist (MV1,5 $\mu \mathrm{M}$ ) and stained with TuJ1. No apparent degeneration was observed over the $16 \mathrm{~h}$ exposure, nor with a panel of other IAP antagonists (data not shown). As a control for the efficacy of MV1 we performed Western blot analysis on parallel cultures and observed degradation of c-IAP1 with two separate antibodies, a hallmark of having reached an efficacious concentration (Varfolomeev et al., 2007). C, We observed strong staining for cleaved Caspase- 9 in $9 \mathrm{~h}$ NGF-deprived DRG explants. D, A Caspase-9 knockout (K0) mouse was generated for the purpose of this study following the published methodology (see Materials and Methods) of removing the catalytic motifin exon 6. To confirm that Caspase-9 expression is lost, we performed Western blot analysis of lysates from E12.5 spinal cord. E, Genetic deletion of Caspase-9 blocked cleavage of Caspase-3 (visualized at $9 \mathrm{~h}$ ) and axon degeneration (visualized at $24 \mathrm{~h}$ ) in NGF-deprived explants. $\boldsymbol{F}$, Application of the BCl-2 antagonist ABT-737 (20 $\mu \mathrm{M}, 3 \mathrm{~h})$ leads to Caspase-3 cleavage in 2 day DRG explants, and the pro-degenerative effects of ABT-737 (20 $\mu \mathrm{M}, 16 \mathrm{~h}$ ) are suppressed in Bax and Caspase-3 $\mathrm{KO}$ cultures in Campenot chambers. $\mathbf{G}$, Axons are visualized by TuJ1 immunoreactivity. $\boldsymbol{H}$, Model for the regulation of axon degeneration in NGF deprived sensory neurons.

treatment can induce more robust cleaved Caspase-3 staining in these cultures suggests that as neurons age in culture, the coupling between neurotrophin signaling and the processing of Caspase- 3 becomes reduced.
Interestingly, a different picture emerged when we deprived entire DRG explants of NGF after just 2 days in culture. In such cultures, axons degenerate much more rapidly than in Campenot chambers and are almost completely degenerated within $16 \mathrm{~h}$. 
Similar to other studies (Kouroku et al., 1998; Schoenmann et al., 2010), and in contrast to what we observed in 7 day cultures (whether explant cultures or in Campenot chambers), we found uniform and strong appearance of cleaved Caspase- 3 throughout the length of the axon at $9 \mathrm{~h}$ (Fig. $4 \mathrm{D}$ ); the signal was absent in axons from Caspase-3 knockout mice. The number of axons in the explant that stained positive for cleaved Caspase-3, as well as the apparent intensity of signal, increased with time (data not shown). Thus, the same axons can show either poorly detectable or highly evident cleavage of Caspase-3, depending on the length of the cultures, presumably reflecting neuronal age.

While the relationship between age in culture and the magnitude of Caspase- 3 cleavage remains to be more fully explored and its basis remains to be determined (see Discussion), these findings begin to resolve the apparent discrepancies in the literature and between experimental paradigms on the extent of detection of cleaved Caspase- 3 in deprived axons.

\section{Caspase- 3 is activated downstream of Bax and the mitochondrial pathway}

Caspase- 3 can be activated through the extrinsic death receptor pathway by Caspase- 8 , or through the intrinsic mitochondrial pathway by Caspase-9. In light of the similar protective effects of Caspase-3 and Bax knockouts, we considered the intrinsic pathway most likely to contribute to activation of Caspase-3. Indeed, we found that axonal staining for cleaved Caspase-3 was eliminated in explants from Bax-knockout DRGs deprived of NGF (data not shown), consistent with recent results (Schoenmann et al., 2010). Following Bax activation, Caspase-3 is cleaved mainly via processing by Caspase- 9 . Activated Caspase- 3 can be inhibited by the X-linked inhibitor of apoptosis (XIAP), an E3 ligase that directly binds and inhibits catalytic activity of Caspase-3 (Salvesen and Duckett, 2002). Cleavage of XIAP has been proposed as a candidate mechanism to disinhibit cleaved Caspase-3 during sensory axon degeneration (Schoenmann et al., 2010). To address this possibility, we performed an NGF deprivation time course on E12.5 DRG explants and isolated axons by physically removing the cell bodies and proximal axons of the explant before lysis (Fig. 5A). In the presence of NGF, Caspase-3 exists as a full-length, inactive zymogen that is subsequently processed into its mature, active form over time. XIAP levels remained constant during this period, suggesting that XIAP degradation is unlikely to account for Caspase-3 activation in our experimental paradigm (Fig. 5A). Since stable XIAP levels during NGF withdrawal do not necessarily rule out a functional role for inhibitor of apoptosis (IAP) proteins, we further interrogated IAP function using pharmacology. If changes in IAP function alone were responsible for Caspase- 3 cleavage, we reasoned that acute IAP antagonism should induce axon degeneration. We tested this hypothesis by incubating DRG explants with the Smac-mimetic MV1. Smac is an endogenous IAP antagonist that functions to dissociate the inhibitory interaction between XIAP and various caspases, and in mimicking this binding interface, MV1 promotes caspase activation (Varfolomeev et al., 2007). However we failed to observe prodegenerative effects of MV1 (Fig. 5B). To ensure that the compound functioned properly, we harvested DRG explants from parallel cultures and observed degradation of c-IAP1, an IAP family member whose abundance is used as an assay for MV1 function (Varfolomeev et al., 2007) (Fig. 5B).

We observed strong staining for cleaved Caspase-9 in NGFdeprived axons (Fig. 5C), consistent with the possibility that
Caspase-9 is the key regulator of Caspase-3 activation. Like Caspase-3, cleavage of Caspase-9 at the inter-subunit linker is commonly used as a surrogate for enzymatic activation; however, it should be noted that the uncleaved zymogen of Caspase- 9 is capable of weak enzymatic function (Stennicke et al., 1999). To further interrogate the role of Caspase- 9 in axon degeneration, we generated a Caspase-9-knockout mouse (Fig. 5D) and assayed Caspase-3 activation and axon degeneration in NGF-deprived Caspase-9-knockout explants. We observed a loss of Caspase-3 cleavage and full protection against NGF withdrawal in the Caspase-9 knockout (Fig. 5E); the degree of protection was equivalent to what we observe in $B a x$ (Nikolaev et al., 2009) and Caspase-3-knockout (Fig. 3A) axons. Together, these data support a model in which Caspase-3 is cleaved through a pathway involving Bax and Caspase- 9 and suggest that IAP proteins may not be strong contributors to the initiation of axon degeneration in this experimental system (Fig. $5 H$ ).

\section{Control of Bax/Caspase-3 activation by the anti-apoptotic Bcl-2 family}

How is the activation of Bax controlled? In healthy cells, Bax is bound by one or more members of the anti-apoptotic Bcl-2 family: Bcl-2, Bcl-Xl, Bcl-w, Mcl-1, and A1. Through a variety of mechanisms, proapoptotic stimuli dissociate this binding and free Bax to initiate apoptosis (Adams and Cory, 1998). Regulation of the antiapoptotic Bcl-2 family is critical to establish the threshold for the induction of apoptosis, and misexpression of these proteins is causative in a number of cancers (Adams and Cory, 2007). Despite their importance, the function of these family members in axons remains largely unexplored. Expression of Bcl-2 did not protect axons from degeneration caused by the pmn mutation (Sagot et al., 1995), whereas expression of $\mathrm{Bcl}-\mathrm{Xl}$ did protect sympathetic axons during NGF withdrawal (Vohra et al., 2010), and genetic deletion of Bcl-w accelerated sensory axon degeneration following neurotrophin withdrawal in vitro and produced an adult-onset axonopathy in vivo (Courchesne et al., 2011). Here we took a loss-of-function pharmacological approach to address the role of this family in axon degeneration in our paradigm.

ABT-737 is a peptidomimetic inhibitor of Bcl-2, Bcl-Xl, and $\mathrm{Bcl}-\mathrm{w}$, designed from the structure of the $\mathrm{BH} 3$ binding interface between these proteins and their endogenous inhibitor Bad (Oltersdorf et al., 2005). As a BH3 mimetic, the compound acts to compete Bax away from its anti-apoptotic Bcl-2 binding partners, thereby activating the mitochondrial pathway. Acute application of ABT737 to wild-type DRG explants led to increased immunoreactivity for cleaved Caspase-3 in axons (Fig. 5F). Further, application to axons in Campenot chambers caused degeneration that morphologically resembles that seen during NGF withdrawal (Fig. 5G). To control for the specificity of the compound, we repeated this experiment in Bax and Caspase-3-knockout axons and found that its prodegenerative effects were fully suppressed, consistent with the model that members of the anti-apoptotic Bcl-2 family are important in restricting Bax activation in axons and suggesting a key role for Bcl-2, $\mathrm{Bcl}-\mathrm{Xl}$, and/or Bcl-w. These data also indicate that Caspase- 3 could also be a key effector of axon degeneration downstream of stimuli distinct from NGF deprivation that activate Bax.

\section{Caspase- 3 and Caspase- 6 contribute to axon pruning in the superior colliculus}

We next addressed whether caspase-dependent mechanisms operate more broadly than in trophic factor-dependent sensory axon degeneration in vitro. To this end we examined a role for Caspase- 3 and Caspase-6 in developmental axon pruning in the retinocollicular system. In mature mice, the projection of retinal ganglion cells 

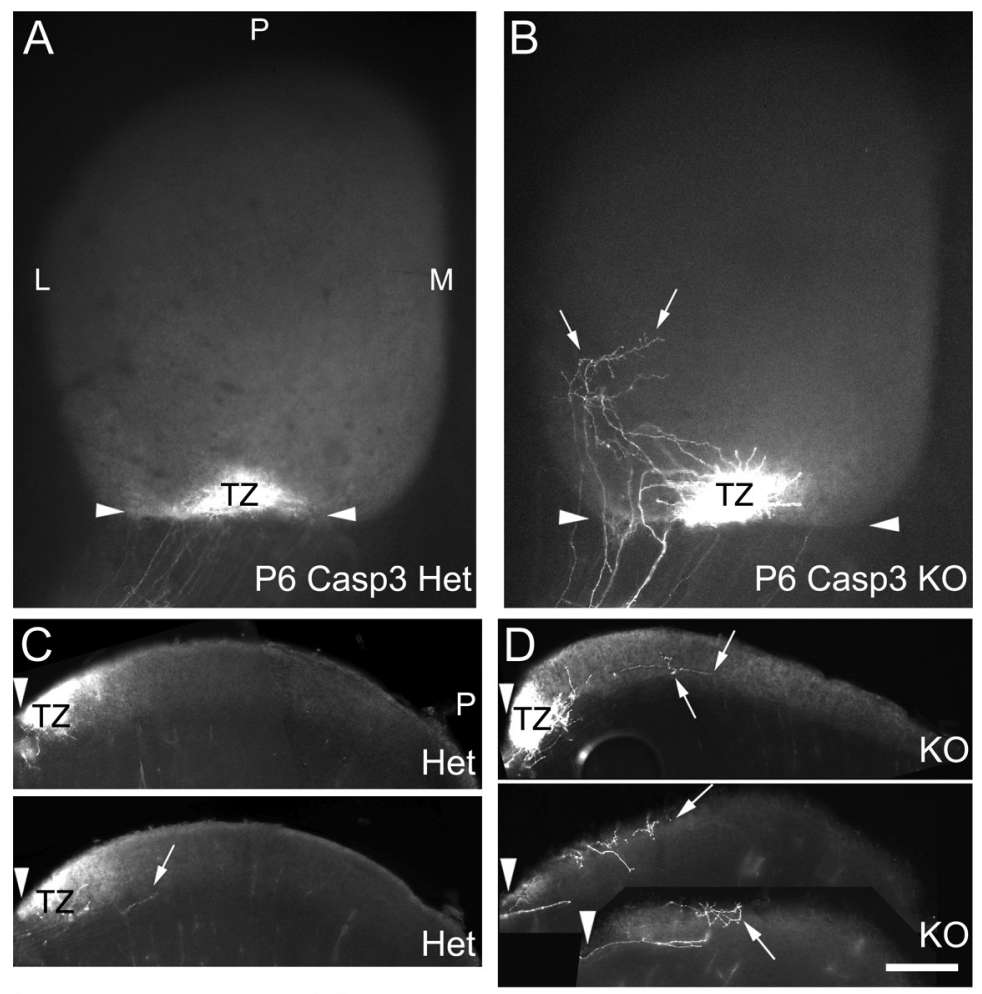

E

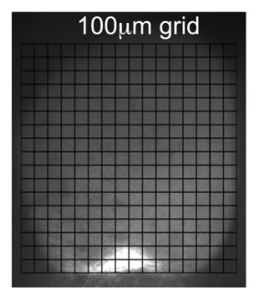

F

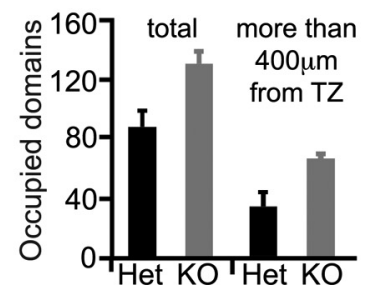

Figure 6. Impaired pruning of retinocollicular axons in Caspase-3 by Dil labeling. A, Superior colliculus from a P6 Caspase-3 heterozygous (P6 Casp Het) mouse $24 \mathrm{~h}$ after focal injection of the lipophilic axon tracer Dil into the periphery of temporal retina. B, SC from a Caspase-3 knockout (KO) P6 mouse $24 \mathrm{~h}$ after focal Dil injection into the periphery of temporal retina. In Caspase-3 K0 mice, an appropriately sized TZ at the appropriate location is observed. In addition, RGC axon segments and rudimentary arbors are maintained in ectopic locations (arrows) posterior (P) and lateral (L) to the TZ. C, D, Vibratome sections (sagittal, $100 \mu \mathrm{m}$ ) through the SC of P6 mice injected as those depicted in $\boldsymbol{A}, \boldsymbol{B}$ are shown. $\boldsymbol{C}$, In Caspase-3 heterozygous mice very few axon segments persist away from the TZ. In addition, arbors are always directly associated with the TZ. D, In Caspase-3 KO mice, axon segments are evident well posterior to the TZ (arrows). In addition, rudimentary arbors are found in aberrant positions hundreds of microns lateral and posterior to the TZ (top and bottom panels). The bottom panel shows sections taken from the case in $\boldsymbol{B}$ from the lateral position of the left arrow. $\boldsymbol{E}$, A grid of $100 \mu \mathrm{m}$ square domains overlaid on a P6 SC. $\boldsymbol{F}$, In Caspase-3 knockout P6 mice, axon segments persist in a significantly greater number of total $100 \mu \mathrm{m}$ square domains outside of the dense TZ (47\% increase, $p<0.05$; Student's $t$ test). This difference is more pronounced in regions more distant to the $\operatorname{TZ}(p<0.05)$. Arrowheads designate the anterior border of the SC. M, Medial. Scale bar (in D), $300 \mu \mathrm{m}$.

(RGCs) to the superior colliculus (SC) is organized into a refined retinotopic map, with temporal retina connecting to anterior SC and nasal retina to posterior SC. In neonatal mice, however, the retinocollicular projection is topographically diffuse, and RGCs throughout the retina project their axons across much of the entire anterior-posterior axis of the SC. The development of a refined topography requires the large-scale pruning of RGC axons. While local competition between axons might impose a de facto trophic deprivation, axon pruning in this system is believed to arise primarily via the action of pro-pruning molecules (McLaughlin and O'Leary, 2005). For example, developmental pruning of these axons is delayed in mice lacking DR6 (Nikolaev et al., 2009), which can signal via an apoptotic cascade (Pan et al., 1998; Nikolaev et al., 2009). We therefore asked whether loss of caspase function would give rise to a similar delay. We began by studying the Caspase-3 knockout through focal DiI injections limited to the periphery of temporal retina of postnatal day $(\mathrm{P})$ 5 animals and subsequent analysis of the retinocollicular projection at $\mathrm{P} 6$. In wildtype and Caspase-3 heterozygous control mice, these focal injections label a refined pattern of dense arborizations restricted to a termination zone (TZ) in the anterior SC (Fig. $6 \mathrm{~A}, \mathrm{C}$ ). In contrast, similar injections in P6 Caspase-3 knockout animals label not only the dense TZ, but also reveal an increase in the number of persisting axons that terminated far from the $\mathrm{TZ}$ compared to heterozygous controls (Fig. 6B,D). Quantitation showed a significant increase in the coverage of the SC by labeled axons in the Caspase-3 knockout animals compared to heterozygous controls (Fig. 6E,F). These findings are consistent with a delay in axon pruning required to develop refined topography.

To expand upon these findings, we examined retinocollicular pruning of central retinal RGC populations in Caspase-3- and Caspase-6-knockout mice labeled by in utero electroporation of a GFP expression plasmid. In control animals, scoring the number of GFPpositive axons in the posterior SC enables the quantitative assessment of developmental axon pruning between P1 and P6 (Fig. 7A-D). Analysis of Caspase-3- and Caspase-6-knockout animals revealed a $\sim 4$-fold increase in the number of GFP+ axons within posterior SC at P6 compared to littermate controls (Fig. 7F, $p<0.025$ ). This increase was not due to a difference in the total number of axons labeled nor the size of the TZ populated by GFP axons between genotypes, as normalization against these variables did not account for the four-fold increase in GFP axons within posterior SC (Fig. 7G-L). Together, these data suggest that both Caspase- 3 and Caspase- 6 are required for the normal timing of retinocollicular axon pruning. Interestingly, animals heterozygous for the Caspase-6-null allele, but not Caspase-3, also exhibited an increase in unpruned axons in posterior SC compared to littermate controls $(p<0.05)$, a phenotype that may reflect differences in enzymatic activity between these two proteases.

The degree of protection from degeneration we observe is of similar magnitude to what has been observed in mice lacking EphA/ EphrinAs, which are thought to participate in triggering pruning (Feldheim and O'Leary, 2010), and in DR6 knockout mice (Nikolaev et al., 2009). While previous studies suggest that DR6 is likely to be upstream of Caspase-3 (Pan et al., 1998; Nikolaev et al., 2009), it will be of interest to determine whether EphA/EphrinA and p75 signaling are also upstream of Caspase- 3 or instead contribute to parallel pruning pathways (Lim et al., 2008). 
A

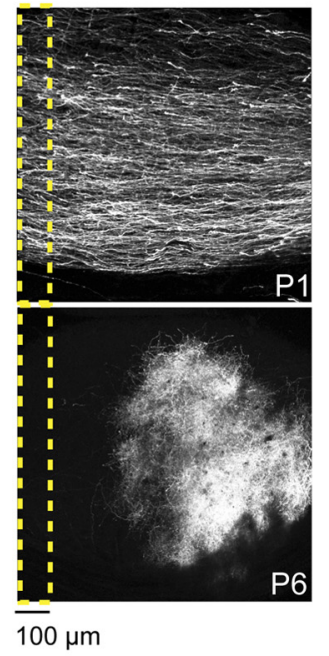

F

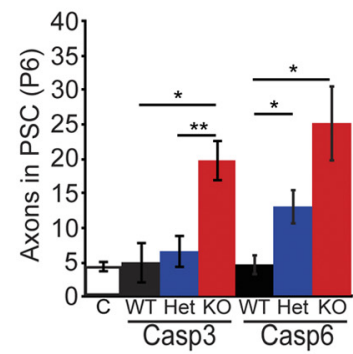

B

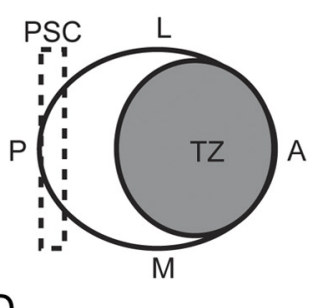

D

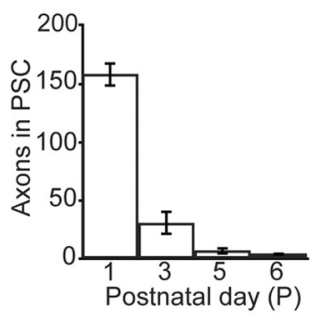

G

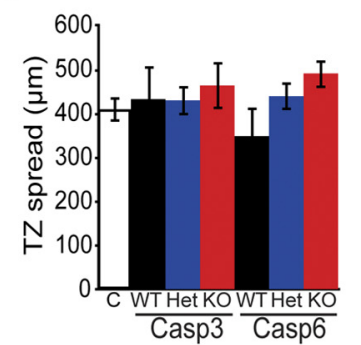

$\mathrm{J}$
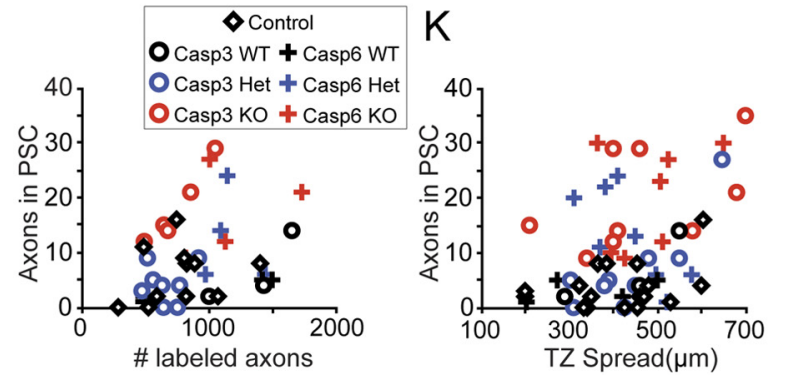

C

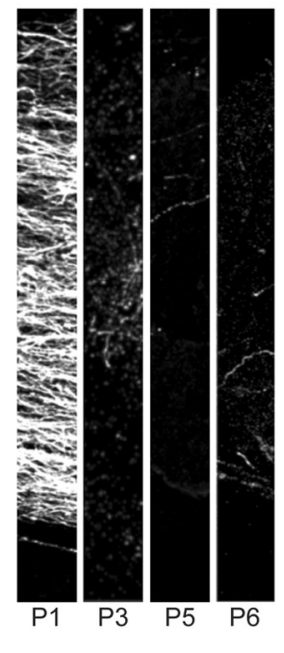

E

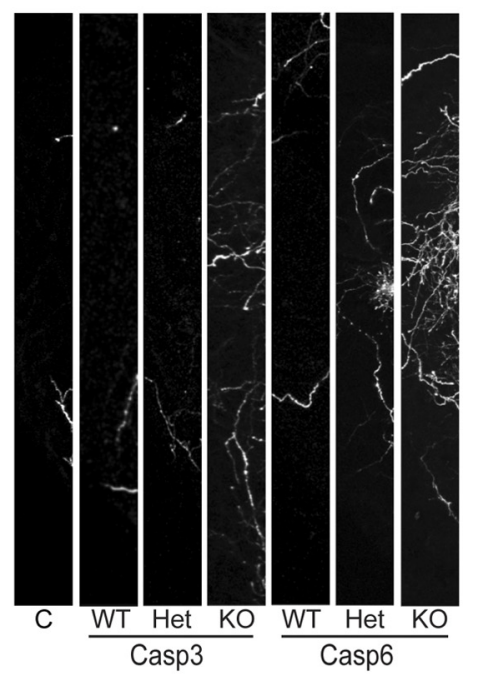

I

$\mathrm{H}$

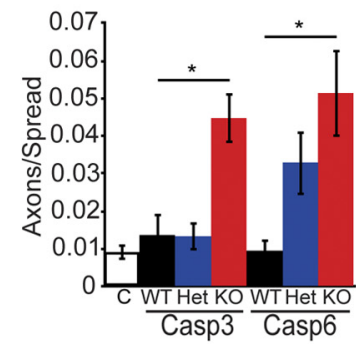

L

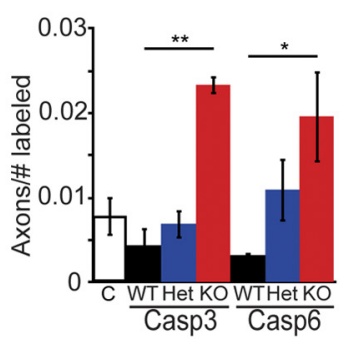

Figure 7. Impaired pruning of retinocollicular axons in Caspase-3 and Caspase- 6 by in utero labeling. $A$, Representative maximum intensity projection images of GFP-positive axons within the SC at postnatal days 1 P1 and P6. Yellow box indicates the PSC. B, Schematic of the left superior colliculus used for GFP-labeling experiments; A, Anterior; P, posterior; M, medial; L, lateral; TZ, termination zone; PSC, posterior superior colliculus defined as the posterior region within $100 \mu \mathrm{m}$ of imaged edge. C, Representative images of the PSC in control animals at postnatal days $1,3,5$, and 6. C, Control; WT, wild type; Het, heterozygous; KO, knockout. D, Quantification of the number of GFP-positive axons in the PSC as a function of developmental age (P1, 158.4 $\pm 10.8, n=5 ;$ P3, $31.7 \pm 10.3, n=6 ; P 5,7.8 \pm 3.5, n=7 ; \mathrm{P} 6,4.9 \pm 1.1, n=15) . E$, Representative images of the PSC in Caspase-3- and Caspase-6-knockout mice. $\boldsymbol{F}$, Quantification of the number of GFP-positive axons in the PSC of Caspase-3 (WT, $5 \pm 3.1, n=4 ;$ Het, $6.6 \pm 2.5, n=10 ; \mathrm{KO}, 19.8 \pm 3.0, n=9$ ) and Caspase-6 mutants (WT, $3.25 \pm 1.0, n=5 ;$ Het, $13 \pm 2.6, n=9 ; \mathrm{KO}, 25.6 \pm 6.3, n=$ 9) at P6. C corresponds to a wild-type P6 control group included throughout. G, Quantification of the spread of GFP labeling along the anterior-posterior axis of the SC as an estimate of the size of the TZ ( $n=17,3,10,9,5,8$, and 9, respectively, for listed genotypes). $\boldsymbol{H}$, Quantification of the number of GFP-positive axons in the optic nerve tract $(n=11,3,9,6,4,4$, and 5 , respectively, for listed genotypes). $\boldsymbol{I}$, Axon number in the PSC normalized to TZ size. J, The number of axons in the PSC plotted per animal as a function of the number of labeled axons within the optic nerve tract. $\boldsymbol{K}$, The number of axons in the PSC plotted per animal as a function of TZ size. L, Axon number in the PSC normalized to the number of labeled axons in the optic nerve tract. Caspase-3 K0 and Caspase-6 KOs exhibit a significant increase in normalized axon density compared to littermate controls $(p<0.04)$. Bar graphs represent mean \pm SEM; ${ }^{*} p<0.05 ;{ }^{* *} p<0.01$.

\section{Discussion}

Our studies reveal a Caspase-3-dependent biochemical pathway regulating axon degeneration after trophic deprivation in vitro and in developmental pruning in vivo, but not following axotomy. They support a model in which loss of NGF triggers activation of Bax by dissociation from members of the anti-apoptotic Bcl-2 family, and active Bax promotes cleavage of Caspase-9, presumably through release of Cytochrome $c$ from mitochondria, and active Caspase- 9 cleaves Caspase- 3 . We show that Caspase- 3 directly processes Caspase- 6 and that cleavage of Caspase- 6 is prevented in Caspase-3 knockout axons. Genetic deletion of Caspase-3 provides more complete axon protection than deletion of Caspase- 6 in in vitro sensory neuron cultures, suggesting that Caspase-3 initiates a program of axon degeneration by cleaving several substrates, Caspase- 6 being only one of them. We also implicate caspases in the pruning of exuberant retinocollicular axons during development, which is impaired to similar extents in Caspase-3 and Caspase-6 knockouts, tentatively supporting a linear pathway of caspase activation governing axon pruning in vivo as well. Importantly, only low levels of Caspase-3 cleavage appear to be required for degeneration, which helps explain why in some studies activation was not detected and why 
partial inhibition with pharmacological agents or siRNA knockdown did not protect.

\section{Defining the role of Caspase- 3 in axon degeneration}

In Drosophila, caspases have been implicated in developmental pruning of sensory dendrites and, recently, in stress-induced degeneration of motor axons (Kuo et al., 2006; Williams et al., 2006; Keller et al., 2011). In mammals, Caspase-3 has been implicated in degeneration of olfactory sensory axons in development and after target cell ablation (Cowan et al., 2001; Cowan and Roskams, 2004). However, defining its role in other systems, such as peripheral axon degeneration after trophic withdrawal, has been challenging, with largely negative data from studies using pharmacological inhibition and conflicting reports of immunohistochemical detection (Finn et al., 2000; Nikolaev et al., 2009; Schoenmann et al., 2010).

These apparent conflicts are echoed here by our findings that axons of Caspase-3 knockout DRG neurons are strongly protected from NGF deprivation in both long-term (7 day Campenot and 7 day explant) cultures and short-term ( 2 day explant) cultures, yet cleaved Caspase- 3 is reliably detected by IHC only in short-term cultures.

This paradox invites the question of whether Caspase- 3 is indeed functioning in sensory axons, or whether protection endowed in Caspase-knockout neurons is instead an indirect consequence of enhanced somatic survival, at least in long-term cultures.

We believe, however, that the weight of evidence supports a direct action of Caspase-3 in axons in not just short-term but also long-term cultures, for several reasons. First, although in longterm cultures cleaved Caspase- 3 is not detected by IHC, it can clearly be seen on Western blots of pure axonal material (Fig. 5A), indicating that IHC is not as sensitive as Western blotting. Second, use of Campenot chambers allows selective NGF deprivation of axons, and in this paradigm axons are completely protected in Caspase-3 knockouts. While retrograde signaling to the cell body still occurs, previous evidence has argued that degeneration is dominated by signaling events local to the axon, since genetic deletion of c-Jun - which is activated retrogradely in cell bodies upon NGF deprivation of just the axon compartment and is required for Caspase- 3 activation in cell bodiesprotects only cell bodies but not axons from degeneration when the axonal compartment is selectively deprived (Ghosh et al., 2011). Third, we found that local application of the $\mathrm{BH} 3$ mimetic ABT-737 selectively to the axonal compartment induces focal axonal degeneration that is blocked in the Caspase- 3 and Bax knockouts. Fourth, in cultures of Caspase-3 heterozygous axons in Campenot chambers, local application of z-DEVD-Fmk to the axonal compartment did protect axons from degeneration. Fifth, $\alpha \mathrm{II}$-spectrin is cleaved at its known Caspase- 3 cleavage site in axons in long-term cultures after trophic deprivation (but not, as expected, after axotomy), as assessed by Western blotting of pure axonal preparations (J. Yang et al., manuscript in preparation).

Collectively, these data argue strongly that failure to detect cleaved Caspase- 3 by IHC in NGF-deprived axons in long-term cultures results from inadequate sensitivity of the IHC method, and that Caspase- 3 is in fact activated locally, albeit at a low level, and is absolutely required for degeneration.

The finding that only a small fraction of the zymogen Caspase- 3 is cleaved to the active form in 7 day explant cultures (Fig. 5A) indicates that efficiency of zymogen conversion is diminished at older ages, which could contribute to the shift toward NGF independence that occurs in these neurons with age. Inter- estingly, the ratio of Bax to Bcl-Xl mRNA decreases between embryonic and postnatal DRGs (Vogelbaum et al., 1998), and exogenous expression of a Bax cDNA confers NGF-sensitivity to NGF-independent postnatal sympathetic neurons (Easton et al., 1997), suggesting that Bax activation is reduced as neurons age, which may explain the reduction in Caspase-3 processing.

The model that only low levels of Caspase-3 are needed for degeneration is supported by the finding that axons heterozygous for Caspase-3, a condition that itself confers no protection, sensitizes axons to protection by z-DEVD-Fmk in long-term cultures (Fig. 3D) - even though wild-type axons are not protected by this compound or by siRNA knockdown (Finn et al., 2000; Nikolaev et al., 2009; Schoenmann et al., 2010). The simplest interpretation is that those manipulations individually do not lower Caspase- 3 activity sufficiently and that further lowering by reducing gene dosage is required to reach a low enough level for protection. Since Caspase- 3 can feed back and cleave Caspase- 9 (Slee et al., 1999; Fujita et al., 2001), z-DEVD-Fmk may protect Caspase-3 heterozygous axons in part by interfering with this feedback and indirectly reducing the levels of cleaved Caspase-3 below the low threshold needed to induce degeneration. Interestingly, unlike axons, sensory cell bodies are protected by z-DEVDFmk or siRNA knockdown (Nikolaev et al., 2009), suggesting that the threshold to inhibit Caspase-3 function enough to protect can vary even within different compartments of the same cell.

Caution in interpreting experiments with inhibitors is further suggested by our finding that Caspase- 6 knockout only confers partial axonal protection against NGF withdrawal in vitro (Fig. 1), in contrast to strong protection by z-VEID-Fmk (Nikolaev et al., 2009; Vohra et al., 2010). However, addition of z-VEID-Fmk onto Caspase- 6 knockout axons increased the protection (data not shown), arguing that $z$-VEID-Fmk protects at least partly by inhibiting other factors in addition to Caspase-6. In fact, despite is use as a Caspase-6 inhibitor, z-VEID-Fmk has been shown to block both Caspase-6 and Caspase-3 (McStay et al., 2008). Knockdown of Caspase- 6 using siRNA also appeared to give stronger protection (Nikolaev et al., 2009) than that observed here for Caspase- 6 knockout axons; this may reflect a difference between acute and chronic inhibition, although we also cannot exclude possible off-target effects of the knockdown. Regardless, our knockout data support a role for Caspase-6 in axon degeneration both in vitro and in vivo.

\section{Activation of Caspase- 6 by Caspase- 3}

Suggested biochemical models for activation of Caspase- 6 based on pharmacological and depletion approaches include Caspase- 6 as either an upstream activator or a downstream effector of Caspase-3 (Hirata et al., 1998; Slee et al., 1999; Graham et al., 2011). Our results suggest caution in relying exclusively on such approaches. In our in vitro cultures, we find that genetic deletion of Caspase- 3 prevents activation of Caspase- 6 and has a stronger protective effect than genetic deletion of Caspase-6, which is as expected if Caspase- 6 is the more downstream protease.

Caspase- 6 has been suggested to function in the absence of Caspase-3 in apoptotic human neurons (LeBlanc et al., 1999) in Alzheimer's (LeBlanc, 2005) and Huntington's (Graham et al., 2006) diseases, and it has been proposed that Caspase- 6 might self-activate (Klaiman et al., 2009; Wang et al., 2010) or be activated by Caspase-1 (Guo et al., 2006) - effects we did not observe (Fig. 2) except at very high, possibly nonphysiological levels of Caspase-1 (data not shown). Our data do not, however, rule out self-activation in some cellular contexts or activation by distinct proteases. They do, however, suggest caution when interpreting a 
failure to detect cleaved Caspase- 3 in degenerating tissue by IHC, which cannot, we believe, be taken as conclusive evidence for lack of a role for Caspase- 3 .

\section{Regulation of axon pruning in vivo}

In vivo, we observed delayed pruning of retinocollicular axons in the Caspase-3 knockout. This defect presumably reflects an axonal site of action, since it is observed after the normal period of RGC cell death and since the Caspase-3 knockout does not show enhanced survival of RGCs (Zeiss et al., 2004). The defect is only a delay not a complete blockade, which could reflect operation of either redundant apoptotic mechanisms or nonapoptotic mechanisms. Interestingly, axon pruning was delayed to an equal degree in Caspase-3 and Caspase-6 knockouts in contrast to sensory axons in vitro, implying that the precise pathway downstream of Caspase-3 might be different in different contexts.

While further studies are therefore required to establish the precise contribution of Caspase- 3 and - 6 to developmental pruning of different axonal populations, our results nonetheless strongly implicate both caspases in axon degeneration both in vitro and in vivo.

\section{References}

Adams JM, Cory S (1998) The Bcl-2 protein family: arbiters of cell survival. Science 281:1322-1326. CrossRef Medline

Adams JM, Cory S (2007) The Bcl-2 apoptotic switch in cancer development and therapy. Oncogene 26:1324-1337. CrossRef Medline

Bagri A, Cheng HJ, Yaron A, Pleasure SJ, Tessier-Lavigne M (2003) Stereotyped pruning of long hippocampal axon branches triggered by retraction inducers of the semaphorin family. Cell 113:285-299. CrossRef Medline

Campenot RB, Walji AH, Draker DD (1991) Effects of sphingosine, staurosporine, and phorbol ester on neurites of rat sympathetic neurons growing in compartmented cultures. J Neurosci 11:1126-1139. Medline

Cheng HJ, Bagri A, Yaron A, Stein E, Pleasure SJ, Tessier-Lavigne M (2001) Plexin-A3 mediates semaphorin signaling and regulates the development of hippocampal axonal projections. Neuron 32:249-263. CrossRef Medline

Courchesne SL, Karch C, Pazyra-Murphy MF, Segal RA (2011) Sensory neuropathy attributable to loss of Bcl-w. J Neurosci 31:1624-1634. CrossRef Medline

Cowan CM, Roskams AJ (2004) Caspase-3 and caspase-9 mediate developmental apoptosis in the mouse olfactory system. J Comp Neurol 474:136148. CrossRef Medline

Cowan CM, Thai J, Krajewski S, Reed JC, Nicholson DW, Kaufmann SH, Roskams AJ (2001) Caspases 3 and 9 send a pro-apoptotic signal from synapse to cell body in olfactory receptor neurons. J Neurosci 21:70997109. Medline

Dikranian K, Cohen R, Mac Donald C, Pan Y, Brakefield D, Bayly P, Parsadanian A (2008) Mild traumatic brain injury to the infant mouse causes robust white matter axonal degeneration which precedes apoptotic death of cortical and thalamic neurons. Exp Neurol 211:551-560. CrossRef Medline

Easton RM, Deckwerth TL, Parsadanian AS, Johnson EM Jr (1997) Analysis of the mechanism of loss of trophic factor dependence associated with neuronal maturation: a phenotype indistinguishable from Bax deletion. J Neurosci 17:9656-9666. Medline

Feldheim DA, O'Leary DD (2010) Visual map development: bidirectional signaling, bifunctional guidance molecules, and competition. Cold Spring Harb Perspect Biol 2:a001768. CrossRef Medline

Finn JT, Weil M, Archer F, Siman R, Srinivasan A, Raff MC (2000) Evidence that Wallerian degeneration and localized axon degeneration induced by local neurotrophin deprivation do not involve caspases. J Neurosci 20: 1333-1341. Medline

Fujita E, Egashira J, Urase K, Kuida K, Momoi T (2001) Caspase-9 processing by caspase-3 via a feedback amplification loop in vivo. Cell Death Differ 8:335-344. CrossRef Medline

Garcia-Frigola C, Carreres MI, Vegar C, Herrera E (2007) Gene delivery into mouse retinal ganglion cells by in utero electroporation. BMC Dev Biol 7:103. CrossRef Medline
Ghosh AS, Wang B, Pozniak CD, Chen M, Watts RJ, Lewcock JW (2011) DLK induces developmental neuronal degeneration via selective regulation of proapoptotic JNK activity. J Cell Biol 194:751-764. CrossRef Medline

Graham RK, Deng Y, Slow EJ, Haigh B, Bissada N, Lu G, Pearson J, Shehadeh J, Bertram L, Murphy Z, Warby SC, Doty CN, Roy S, Wellington CL, Leavitt BR, Raymond LA, Nicholson DW, Hayden MR (2006) Cleavage at the caspase- 6 site is required for neuronal dysfunction and degeneration due to mutant huntingtin. Cell 125:1179-1191. CrossRef Medline

Graham RK, Ehrnhoefer DE, Hayden MR (2011) Caspase-6 and neurodegeneration. Trends Neurosci 34:646-656. CrossRef Medline

Guo H, Pétrin D, Zhang Y, Bergeron C, Goodyer CG, LeBlanc AC (2006) Caspase- 1 activation of caspase- 6 in human apoptotic neurons. Cell death and differentiation 13:285-292. CrossRef Medline

Hakem R, Hakem A, Duncan GS, Henderson JT, Woo M, Soengas MS, Elia A, de la Pompa JL, Kagi D, Khoo W, Potter J, Yoshida R, Kaufman SA, Lowe SW, Penninger JM, Mak TW (1998) Differential requirement for caspase 9 in apoptotic pathways in vivo. Cell 94:339-352. CrossRef Medline

Hirata H, Takahashi A, Kobayashi S, Yonehara S, Sawai H, Okazaki T, Yamamoto K, Sasada M (1998) Caspases are activated in a branched protease cascade and control distinct downstream processes in Fasinduced apoptosis. J Exp Med 187:587-600. CrossRef Medline

Keller LC, Cheng L, Locke CJ, Müller M, Fetter RD, Davis GW (2011) Glialderived prodegenerative signaling in the Drosophila neuromuscular system. Neuron 72:760-775. CrossRef Medline

Klaiman G, Champagne N, LeBlanc AC (2009) Self-activation of Caspase-6 in vitro and in vivo: Caspase- 6 activation does not induce cell death in HEK293T cells. Biochim Biophys Acta 1793:592-601. CrossRef Medline

Knudson CM, Tung KS, Tourtellotte WG, Brown GA, Korsmeyer SJ (1995) Bax-deficient mice with lymphoid hyperplasia and male germ cell death. Science 270:96-99. CrossRef Medline

Kouroku Y, Urase K, Fujita E, Isahara K, Ohsawa Y, Uchiyama Y, Momoi MY, Momoi T (1998) Detection of activated Caspase-3 by a cleavage sitedirected antiserum during naturally occurring DRG neurons apoptosis. Biochem Biophys Res Commun 247:780-784. CrossRef Medline

Kuida K, Zheng TS, Na S, Kuan C, Yang D, Karasuyama H, Rakic P, Flavell RA (1996) Decreased apoptosis in the brain and premature lethality in CPP32-deficient mice. Nature 384:368-372. CrossRef Medline

Kuida K, Haydar TF, Kuan CY, Gu Y, Taya C, Karasuyama H, Su MS, Rakic P, Flavell RA (1998) Reduced apoptosis and cytochrome $c$-mediated caspase activation in mice lacking caspase 9. Cell 94:325-337. CrossRef Medline

Kuo CT, Zhu S, Younger S, Jan LY, Jan YN (2006) Identification of E2/E3 ubiquitinating enzymes and caspase activity regulating Drosophila sensory neuron dendrite pruning. Neuron 51:283-290. CrossRef Medline

LeBlanc AC (2005) The role of apoptotic pathways in Alzheimer's disease neurodegeneration and cell death. Curr Alzheimer Res 2:389-402. CrossRef Medline

LeBlanc A, Liu H, Goodyer C, Bergeron C, Hammond J (1999) Caspase-6 role in apoptosis of human neurons, amyloidogenesis, and Alzheimer's disease. J Biol Chem 274:23426-23436. CrossRef Medline

Lim YS, McLaughlin T, Sung TC, Santiago A, Lee KF, O’Leary DD (2008) p75(NTR) mediates ephrin-A reverse signaling required for axon repulsion and mapping. Neuron 59:746-758. CrossRef Medline

Low LK, Liu XB, Faulkner RL, Coble J, Cheng HJ (2008) Plexin signaling selectively regulates the stereotyped pruning of corticospinal axons from visual cortex. Proc Natl Acad Sci U S A 105:8136-8141. CrossRef Medline

McLaughlin T, O'Leary DD (2005) Molecular gradients and development of retinotopic maps. Annu Rev Neurosci 28:327-355. CrossRef Medline

McLaughlin T, Torborg CL, Feller MB, O’Leary DD (2003) Retinotopic map refinement requires spontaneous retinal waves during a brief critical period of development. Neuron 40:1147-1160. CrossRef Medline

McStay GP, Salvesen GS, Green DR (2008) Overlapping cleavage motif selectivity of caspases: implications for analysis of apoptotic pathways. Cell Death Differ 15:322-331. CrossRef Medline

Nikolaev A, McLaughlin T, O'Leary DD, Tessier-Lavigne M (2009) APP binds DR6 to trigger axon pruning and neuron death via distinct caspases. Nature 457:981-989. CrossRef Medline

Oltersdorf T, Elmore SW, Shoemaker AR, Armstrong RC, Augeri DJ, Belli BA, Bruncko M, Deckwerth TL, Dinges J, Hajduk PJ, Joseph MK, Kitada 
S, Korsmeyer SJ, Kunzer AR, Letai A, Li C, Mitten MJ, Nettesheim DG, Ng S, Nimmer PM, et al. (2005) An inhibitor of Bcl-2 family proteins induces regression of solid tumours. Nature 435:677-681. CrossRef Medline

Pan G, Bauer JH, Haridas V, Wang S, Liu D, Yu G, Vincenz C, Aggarwal BB, Ni J, Dixit VM (1998) Identification and functional characterization of DR6, a novel death domain-containing TNF receptor. FEBS Lett 431:351356. CrossRef Medline

Park KJ, Grosso CA, Aubert I, Kaplan DR, Miller FD (2010) p75NTRdependent, myelin-mediated axonal degeneration regulates neural connectivity in the adult brain. Nat Neurosci 13:559-566. CrossRef Medline

Plachta N, Annaheim C, Bissière S, Lin S, Rüegg M, Hoving S, Müller D, Poirier F, Bibel M, Barde YA (2007) Identification of a lectin causing the degeneration of neuronal processes using engineered embryonic stem cells. Nat Neurosci 10:712-719. CrossRef Medline

Raff MC, Whitmore AV, Finn JT (2002) Axonal self-destruction and neurodegeneration. Science 296:868-871. CrossRef Medline

Sagot Y, Dubois-Dauphin M, Tan SA, de Bilbao F, Aebischer P, Martinou JC, Kato AC (1995) Bcl-2 overexpression prevents motoneuron cell body loss but not axonal degeneration in a mouse model of a neurodegenerative disease. J Neurosci 15:7727-7733. Medline

Salvesen GS, Duckett CS (2002) IAP proteins: blocking the road to death's door. Nat Rev Mol Cell Biol 3:401-410. CrossRef Medline

Saxena S, Caroni P (2007) Mechanisms of axon degeneration: from development to disease. Prog Neurobiol 83:174-191. CrossRef Medline

Schoenmann Z, Assa-Kunik E, Tiomny S, Minis A, Haklai-Topper L, Arama E, Yaron A (2010) Axonal degeneration is regulated by the apoptotic machinery or a NAD +-sensitive pathway in insects and mammals. J Neurosci 30:6375-6386. CrossRef Medline

Singh KK, Park KJ, Hong EJ, Kramer BM, Greenberg ME, Kaplan DR, Miller FD (2008) Developmental axon pruning mediated by BDNF-p75NTRdependent axon degeneration. Nat Neurosci 11:649-658. CrossRef Medline

Slee EA, Harte MT, Kluck RM, Wolf BB, Casiano CA, Newmeyer DD, Wang HG, Reed JC, Nicholson DW, Alnemri ES, Green DR, Martin SJ (1999) Ordering the cytochrome c-initiated caspase cascade: hierarchical activation of caspases-2, $-3,-6,-7,-8$, and -10 in a caspase-9-dependent manner. J Cell Biol 144:281-292. CrossRef Medline

Stanger K, Steffek M, Zhou L, Pozniak CD, Quan C, Franke Y, Tom J, Tam C, Elliott JM, Lewcock JW, Zhang Y, Murray J, Hannoush RN (2012) Allosteric peptides bind a caspase zymogen and mediate caspase tetramerization. Nat Chem Biol 8:655-660. CrossRef Medline
Stennicke HR, Deveraux QL, Humke EW, Reed JC, Dixit VM, Salvesen GS (1999) Caspase-9 can be activated without proteolytic processing. J Biol Chem 274:8359-8362. CrossRef Medline

Uribe V, Wong BK, Graham RK, Cusack CL, Skotte NH, Pouladi MA, Xie Y, Feinberg K, Ou Y, Ouyang Y, Deng Y, Franciosi S, Bissada N, Spreeuw A, Zhang W, Ehrnhoefer DE, Vaid K, Miller FD, Deshmukh M, Howland D, Hayden MR (2012) Rescue from excitotoxicity and axonal degeneration accompanied by age-dependent behavioral and neuroanatomical alterations in caspase-6-deficient mice. Hum Mol Genet 21:1954-1967. CrossRef Medline

Varfolomeev E, Blankenship JW, Wayson SM, Fedorova AV, Kayagaki N, Garg P, Zobel K, Dynek JN, Elliott LO, Wallweber HJ, Flygare JA, Fairbrother WJ, Deshayes K, Dixit VM, Vucic D (2007) IAP antagonists induce autoubiquitination of c-IAPs, NF-kappaB activation, and TNFalpha-dependent apoptosis. Cell 131:669-681. CrossRef Medline

Vogelbaum MA, Tong JX, Rich KM (1998) Developmental regulation of apoptosis in dorsal root ganglion neurons. J Neurosci 18:8928-8935. Medline

Vohra BP, Sasaki Y, Miller BR, Chang J, DiAntonio A, Milbrandt J (2010) Amyloid precursor protein cleavage-dependent and -independent axonal degeneration programs share a common nicotinamide mononucleotide adenylyltransferase 1-sensitive pathway. J Neurosci 30:13729-13738. CrossRef Medline

Walsh JG, Cullen SP, Sheridan C, Lüthi AU, Gerner C, Martin SJ (2008) Executioner caspase- 3 and caspase-7 are functionally distinct proteases. Proc Natl Acad Sci U S A 105:12815-12819. CrossRef Medline

Walters J, Pop C, Scott FL, Drag M, Swartz P, Mattos C, Salvesen GS, Clark AC (2009) A constitutively active and uninhibitable caspase- 3 zymogen efficiently induces apoptosis. Biochem J 424:335-345. CrossRef Medline

Wang XJ, Cao Q, Liu X, Wang KT, Mi W, Zhang Y, Li LF, LeBlanc AC, Su XD (2010) Crystal structures of human caspase 6 reveal a new mechanism for intramolecular cleavage self-activation. EMBO Rep 11:841-847. CrossRef Medline

Whitmore AV, Lindsten T, Raff MC, Thompson CB (2003) The proapoptotic proteins Bax and Bak are not involved in Wallerian degeneration. Cell Death Differ 10:260-261. CrossRef Medline

Williams DW, Kondo S, Krzyzanowska A, Hiromi Y, Truman JW (2006) Local caspase activity directs engulfment of dendrites during pruning. Nat Neurosci 9:1234-1236. CrossRef Medline

Zeiss CJ, Neal J, Johnson EA (2004) Caspase-3 in postnatal retinal development and degeneration. Invest Ophthalmol Vis Sci 45:964-970. CrossRef Medline 